\title{
The New Paradigm of the Omnichannel Retailing: Key Drivers, New Challenges and Potential Outcomes Resulting from the Adoption of an Omnichannel Approach
}

\author{
Aiolfi Simone ${ }^{1} \&$ Edoardo Sabbadin ${ }^{2}$ \\ ${ }^{1} \mathrm{PhD}$ Candidate, Department of Economics, University of Ferrara, Italy \\ ${ }^{2}$ Associate Professor, Department of Economics, University of Parma, Italy \\ Correspondence: Aiolfi Simone, PhD Candidate, Department of Economics, University of Ferrara, Italy. E-mail: \\ simone.aiolfi@unipr.it
}

Received: October 25, 2017

Accepted: November 28, 2017 Online Published: December 20, 2017

doi:10.5539/ijbm.v13n1p85

URL: https://doi.org/10.5539/ijbm.v13n1p85

\begin{abstract}
The rise of the Internet, mobile technologies and digital disruption have changed the retail business as well as the implementation of the levers of retail mix and the behavior of shoppers. Online channel has become an appealing channel where retailers can sell their products and services. The proliferation of channels and touch points has affected not only consumer behavior but also companies' business models. Many retailers have started to develop multichannel and omnichannel strategies by adding new channels through which interact with the customers. Retailers are now concentrating on how shoppers are influenced by new technologies and how they switch across channels during their research and buying process. Omnichannel retailing, defined as the conceptualization of the complete integration of all channels, with no distinction between the online and the physical channel, is the new retailing paradigm of today. The topic itself is particularly relevant as technological development continue to disrupt retail strategies and practitioners are debating as to how to respond. Particularly, managers are worried about how to manage the several touch points, which are now simultaneously available to customers. Concerning with the present research, we attempt to describe this development by analyzing the existing literature about topics that we can classify within the omnichannel paradigm. In order to explain how both literature and business models are moving from multichannel retailing towards the implementation of omnichannel strategies, we follow a blended approach based on literature review, theoretical background as well as some interesting managerial insights resulting from business' case histories. To address the concerns of managers and retailers about the new challenges they will need to face in implementing an omnichannel retailing approach, we present a theoretical framework, concerning with the adoption of the omnichannel as an innovative strategy in the overall marketing strategies. To deal with the topic we start from three research questions that guide our literature review as well as our theoretical framework. We investigate what are the key drivers that have stimulated retailers to develop an omnichannel retailing strategy, what are the new challenges that retailers will need to face when they decide to implement an omnichannel strategy in their overall marketing strategy and finally what are the possible outcomes of a correct and successful implementation of an omnichannel retailing strategy. Therefore, our theoretical framework explains key drivers, new challenges and potential outcomes coming from the adoption of the omnichannel retailing in order to help managers and practitioners who might decide to enter the omnichannel retailing.
\end{abstract}

Keywords: Channel integration, omnichannel, online-offline retailing, digital disruption, mobile channel

\section{Introduction}

The success of the online channel and the subsequent ongoing digitalization have, over the past twenty years, drastically changed the way of living and the retail landscape as well. The disruptive development in new technologies, the proliferation of channels and touch-points, through which customers can interact with firms, as well as the rapid proliferation of broadband connection in people's home, with more and more shoppers that are always connected, have led to unprecedented growth of research and acquisition of products through internet (Pentina and Hasty, 2009). As a result, the internet has grown as a major sales and distribution channel for the sales of goods, particularly fast moving consumer goods, and e-commerce as well as m-commerce (mobile 
commerce) impact deeply on supply chains (Johnson and Whang, 2002). The integration of e-commerce and the physical channels creates opportunities for synergies that allow companies to offer different services through both different channels and different targets in terms of age groups. Internet retailing is creating greater value for the customer in terms of additional services as well as major touch-points with the company. Therefore, the rise of the Internet channel in a service dominant prospective tends to increase the frequency of interactions between customers and retailers. The increasing success of the online channel will have a significant impact not only on the management but also on consumer behavior.

To deal with these technological improvements, many retailers have developed multichannel strategies by adding to their portfolios new touch-points through which firms can interact with consumers (Verhoef et al., 2007; Blattberg et al., 2008). In order to manage the competition and to establish a better relationship with consumers, retailers consider issues such as customer management and the integration of the retail mix across channels (Neslin et al., 2006). The majority of big grocery retailers has become multi-channel retailers, and nowadays more and more retailers are becoming even omnichannel retailers. We are moving toward a new stage of the multi-channel retailing. Particularly, with the advent of the mobile channel, tablet, social media and their integration of these new channels in the online-offline retailing strategies, the retail landscape has continued to change. We are moving from the paradigm of multi-channel retailing to a model of omnichannel one (Rigby, 2011). Brynjolfsson et al. (2013) argue: "In the past, brick-and-mortar retail stores were unique in allowing consumers to touch and feel merchandise and provide instant gratification; Internet retailers, meanwhile, tried to woo shoppers with wide product selection, low prices and content such as product reviews and ratings. As the retailing industry evolves toward a seamless "omnichannel retailing" experience, the distinctions between physical and online will vanish, turning the world into a showroom without walls" (Brynjolfsson et al., 2013). The most successful and profitable retailers are integrating their virtual and physical presences with the aim to deliver more immersive and convenient, connected experiences to their customers (Planet Retail, 2016 a). The most engaging and efficient omnichannel retailers are able to provide transparency on merchandise, to connect with shoppers across all channels, to meet customer demand immediately, to make shopping easy and convenient as well as to personalize offers based on data analytics and to create a relevant, engaging and seamless shopping experience (Planet Retail, 2016 a).

The topic itself is particularly relevant as technological developments continue to disrupt retail strategies and practitioners are debating as to how to respond. Particularly, practitioners are worried about how to manage the numerous touch points and channels now simultaneously available to customers. Despite its increasing importance in practice, research and conceptualizations on the new omnichannel paradigm seem to be scares, while most of the contributions focus on the multichannel retailing. Given the importance of this development, we believe that a thorough discussion of this movement will be useful for future research. Once discussed the mainstream research within multichannel strategies, we will consider how the literature is now moving from multichannel retail towards the implementation of omnichannel strategies. We will therefore consider articles and research topics concerning both multichannel and omnichannel paradigm. In this research, we present our theoretical framework concerning with the adoption of the omnichannel strategies in the overall marketing strategies of the retailers according to our own literature review. Key drivers, new challenges and the potential outcomes of the adoption of the omnichannel retailing are explained in our theoretical framework. We merge literature and theoretical background with some interesting insights obtained from past researches that may be useful for future researches and for managers who might decide to enter the omnichannel retailing.

The paper is organized as follows. First, a literature review regarding the shift from multichannel retailing to omnichannel retailing (par. 2). Secondly, we present our question research about the rise of the omnichannel retailing and its contextual adoption by the retailers (par. 3). In the same section, we discuss our theoretical framework about the adoption of the omnichannel retailing built on insights and managerial implications coming from literature overview (par. 3). Finally, the last section is devoted to conclusion, limitations and future directions (par. 4).

\section{Multichannel and Omnichannel Retailing: The Move to an Omnichannel World}

The first researchers that defined the concept of channel integration as the degree to which different channels interact with each other were Bendoly et al. (2005). The term channel means a customer touch-point, or a means through which the enterprise can interact with the customers. In literature, previous studies have considered separately offline channels (bricks-and-mortar), and online channels (e-commerce sites/web stores, traditional direct marketing channels, catalogs etc.) (Verhoef et al., 2007). Subsequently, the shopping experience has become increasingly multichannel. Consumers do not only shop in brick-and-mortar stores, but also through various digital channels such as smartphones, mobile applications, and catalogues (Ganesan et al., 2009; 
McCormick et al., 2014). This is why there are some studies on multichannel segmentation (Konus et al., 2008), studies on the effects of the addition of the online channel, as well as the migration of customers from offline channel to the online channel, the buying behavior of customers, customer profitability and customer loyalty in the online channel (Geyskens et al., 2002; Ansari et al., 2008; Van Nierop et al., 2011; Gensler et al., 2012; Homburg et al., 2014). Literature has recently focused on multichannel strategies because of the growth of the online channel and its impacts on companies and customers. Scholars state that, in the early stages of development, companies managed the online channel separately from other corporate strategies with only limited integration (Verhoef, 2012). Nevertheless, it remains an important subject of research, whereas several studies have addressed this topic (Neslin et al., 2006; Patricio et al., 2008; Neslin and Shankar, 2009) as well as channel integration in terms of assortment and prices (Pan et al., 2004). The rise of new digital channels and particularly of that of the mobile channel and mobile apps (Xu et al., 2014) has resulted in disruptive changes in retailing context (Rigby, 2011). Both customers and companies use different channels and touch points constantly, simultaneously and interchangeably in order to facilitate retail customer experience. Today we talk no longer only about multichannel strategies. We talk about omnichannel strategies (Brynjolfsson et al., 2013; Neslin et al., 2014).

\subsection{Multichannel Retailing}

The proliferation of channels has created several challenges for companies that should manage this new environment effectively and efficiently. Multi-channel management and customer relationships become key challenges for firms and managers with the aim to improve their decision making. Neslin et al. (2006) proposed an interesting definition of Multichannel Customer Management (MCM): "multichannel customer management is the design, deployment, coordination, and evaluation of channels through which firms and customers interact, with the goal of enhancing customer value through effective customer acquisition, retention, and development".

Literature has identified two possible multichannel growth strategies: one from clicks to bricks (Pauwels and Neslin, 2015) and the other from bricks to clicks (Gulati and Garino, 1999; Kumar et al., 2012). The first one is to add brick and mortar stores (Pauwels and Neslin, 2015). Many companies that were only online players (the so-called pure players) decided to open physical stores with their brand. Companies like Amazon, Apple, Dell Computer, Bonobos and JustFab are considered as the pioneers of the brick and mortar integration. Dell Computer, which built its business on direct marketing model, used to sell its products through the major American retailers like Best Buy and Wal-Mart. The first Amazon's offline store was a bookstore in San Diego, called Amazon Books, where 5000 titles were displayed according to the online responses of the customers. Amazon's goal is twofold: to embrace the audience still reluctant to rely only on the network and provide a showcase for books that are published directly from Amazon. At the beginning of 2017, Amazon has 29 pop-up stores in the US and it is aggressively expanding its offline presence in the retail market, by opening new pop-up stores in US shopping malls over the next years. The pop-up stores reflect the company's mission of growing in sales reaching consumers directly through a variety of access points including retail storefronts, home delivery, and other innovative formats and devices. An innovative offline store by Amazon is Amazon Go, a new kind of store with no checkout required. Amazon has created a "Just Walk Out Shopping experience" simply using the Amazon Go app to enter the store, shoppers can choose the product they want, and leave without a checkout. The first Amazon Go store is located in Seattle and is opened only to the employees who are testing the new approach, since early 2017 (Amazon.com, 2017).

Other online retailers have recently decided to open offline stores trying to add value to their strategies thanks to what they have learned from their success online. Online stores, in fact, have offered retailers valuable advantages of no traditional retailer overhead, broader reach, personalized recommendations and customer activity tracking, thanks to the online big data. The strategy of adding physical stores is a way to obtain a larger and more satisfied customer base and hence more revenue by creating a personalized experience to their customers. In this way, they are not only looking to create a physical presence, but also to create a unique brand experience (Pauwels and Neslin, 2015). The second strategy relates to physical retailers that add the online channel in their overall strategies. The online channel and its supply chain differ from its offline version for different elements such as customer types, operations of order fulfillment, cost structure, profit contributions, priority in the rationing, logistical requirements, expectations of service quality, degree of market segmentation, access to demand/supply information, and returns policies (Kumar et al., 2012). Thus becomes important to study different aspects of companies engaged in selling over the Internet. Internet retailing is a new format that some retailers have adopted as a result of the evolution of e-commerce. Many of the retail companies are recognizing that success in the new economy will go to those who can apply bricks-and-clicks strategies that bridge the physical and virtual worlds (Gulati and Garino, 1999). 
To cope with the new situation, many retailers have implemented multi-channel strategies. Particularly, they have faced the choice of whether new channels should be added to the existing channel mix (Deleersnyder et al., 2002; Geyskens et al., 2002). This decision involves both the traditional brick-and-mortar players, and the new online pure-players, who face the question of whether they should be available offline as well (Avery et al., 2012). Many of the largest retailers (such as Wal-Mart, Costco, Kroger, Carrefour and Tesco), manufactures (like Procter \& Gamble and Ford) and catalog marketing (such as Lands' End and L.L. Bean) have integrated online retailing in their existing strategies (Grewal et al., 2004). An emerging trend in 2016 is the moving online of the discounter that become the fastest growing grocery online (+6.1\% CAGR, 2016-2021) (Planet Retail, 2016 b). Discounters such as Lidl and Aldi attempt to broaden their appeal to more customers offering expanded ranges of products such as wine and non-food (Planet Retail, 2016 b). As far as the grocery sector, literature suggests that the online grocery business started with home deliveries in France, when Chronodrive introduced, in 2004, the "click-and-collect", a method that is growing more popular among omnichannel customers, in both grocery and other retail sectors. For long time, France was the leader in online grocery business and it is still a leading market in "click-and drive" through grocery stores managed by Carrefour (Planet Retail, 2016 b). Today grocery business has developed from pure play through bricks-and-clicks and multichannel into omnichannel retailing (Grewal et al., 2009).

\subsection{Omnichannel Retailing}

While in the past years there was a clear distinction between brick-and-mortar stores and online stores, the recent trend of channel integration has led the separated sales channels to interweave with each other. The term multichannel, appeared for the first time in 2000's (Lazaris and Vrechopoulos, 2014), starts to be replaced by the term omnichannel, first introduced in 2009. Academic literature on omnichannel retailing has started appearing since those years and during 2015, the amount of academic articles about omnichannel retailing has accelerated (Verhoef et al., 2015). The new paradigm has still many different meanings: it can refer to a survival strategy (McCormick et al., 2014; Regalado, 2013), a singular seamless operation (McCormick et al., 2014) or it can mean a service designed for customers whenever and wherever (Fairchild, 2014). Omnichannel is defined as the phenomenon for which the customers consider all the retailer's sales and marketing channels as one entity, and the shopping experience is seamless regardless of which channels the customer uses (Herhausen et al., 2015). The omnichannel customers use simultaneously all or many available sales channels during their buying process while multichannel customer uses different sales channels in parallel (Lazaris and Vrechopoulos, 2014). Thus, omnichannel retailing is the conceptualization of the complete integration of all channels (Rigby, 2011; Klosek, 2012; Frazer and Stiehler, 2014). The digital and physical worlds are blending without any distinctions between them, either on the customer or the company's perspective (Rigby, 2011). While multichannel implies a division between the physical and online store, in the omnichannel context customers move freely between the online, mobile devices, and physical store, all within a single transaction process (Rosenblum and Kilcourse, 2013). Omnichannel management provides for a synergistic management of the many available channels and customer touch points so that the experience of clients through multiple channels is optimized (Herhausen et al., 2015). Often the terms multichannel and omnichannel are mixed due to the nature of digital world and retailing. Nevertheless, literature of nowadays is starting to separate the two concepts, defining omnichannel retailing as a separate paradigm.

To understand better the diversity of retailing through multiple channels, Beck and Rygl (2015) proposed a formal categorization of multiple channel retailing in multi, cross and omnichannel in terms of academic articles. The authors identify two dimensions of channel interaction and integration to classify multiple channel retailing. The first is related to whether channel interaction can be triggered by the customers or is controlled by the retailer. The second is concerned with how many and what channels are considered. Beck and Rygl (2015) defined the concepts of multi, cross and omnichannel retailing and they evaluated academic articles as follows. Multichannel retailing is the set of activities involved in selling merchandise or service through more than one channel or all channel widespread at the same time but customers can trigger no interaction and/or the retailer controls no integration. Crosschannel retailing is the set of activities involved in selling merchandise or service through more than one channel or all channel widespread at the same time but with a partial interaction with the customers and/or a partial integration controlled by the retailer. Retailing can also be classified as crosschannel when a retailer sells through more than one channel but not all widespread channels with full interaction triggered by customers and/or full integration controlled by retailer. Finally, Omnichannel retailing is the set of activities involved in selling merchandise or service through all widespread channels at the same time with full interaction triggered by customer and full integration controlled by retailer (Beck and Rygl, 2015).

As crosschannel and especially omnichannel strategies become prevalent among retailing researchers, literature 
has started to investigate interesting issues about several challenges of the implementation of the omnichannel strategies (Bell et al., 2013; Brynjolfsson et al., 2013; Lewis et al., 2013; Strang, 2013). Researchers have tried to answer to questions about how a multichannel retailer moves towards an omnichannel strategy and which challenges are faced in the process (Herhausen et al., 2015). This topic has become critical for retailers and their supply chain partners and it will stress them to review and revise their competitive strategies (Brynjolfsson et al., 2013).

\section{The Rise of the Omnichannel Retailing: Insights and Managerial Implications from Literature Overview}

Over the years, literature has explained some key drivers and challenges at the basis of the retailers' decisions to implement an omnichannel strategy: motivators that have influenced the omnichannel development, symbolizing the incentives for a single retailer to offer its customers an omnichannel shopping experience, and challenges that retailers might face when implementing an omnichannel strategy.

In this section, we present our theoretical framework about the adoption of the omnichannel strategies in the overall retailers' marketing strategies. Our theoretical framework explains key drivers, mew challenges and the possible outcomes of a successful adoption of the omnichannel retailing. We have developed the proposed framework merging literature and theoretical background with some interesting insights obtained from past and recent researches. The framework might be useful for further researches and for managers who might decide to enter the omnichannel retailing. Managers should take in account our framework when they decide to develop an omnichannel strategy. Therefore, managers might address better their marketing efforts and capture the goodwill of consumers, increasing the engagement of the customers and creating a long lasting relationship with them.

To deal with the topic we have started from three research questions that have guided our literature review as well as the theoretical framework proposed in figure 1 .

Q1) What are the key drivers that have stimulated retailers to develop an omnichannel retailing strategy?

Q2) What are the challenges that retailers must face when they decide to implement an omnichannel strategy in their overall marketing strategy?

Q3) What are the potential outcomes of a correct and successful implementation of an omnichannel retailing strategy?

In the sections below we present the key drivers we have identified (par 3.1), then the new challenges the retailers have to face in an omnichannel world (par 3.2) and finally the potential outcomes deriving from literature overview and successful retailing cases studies (par 3.3).

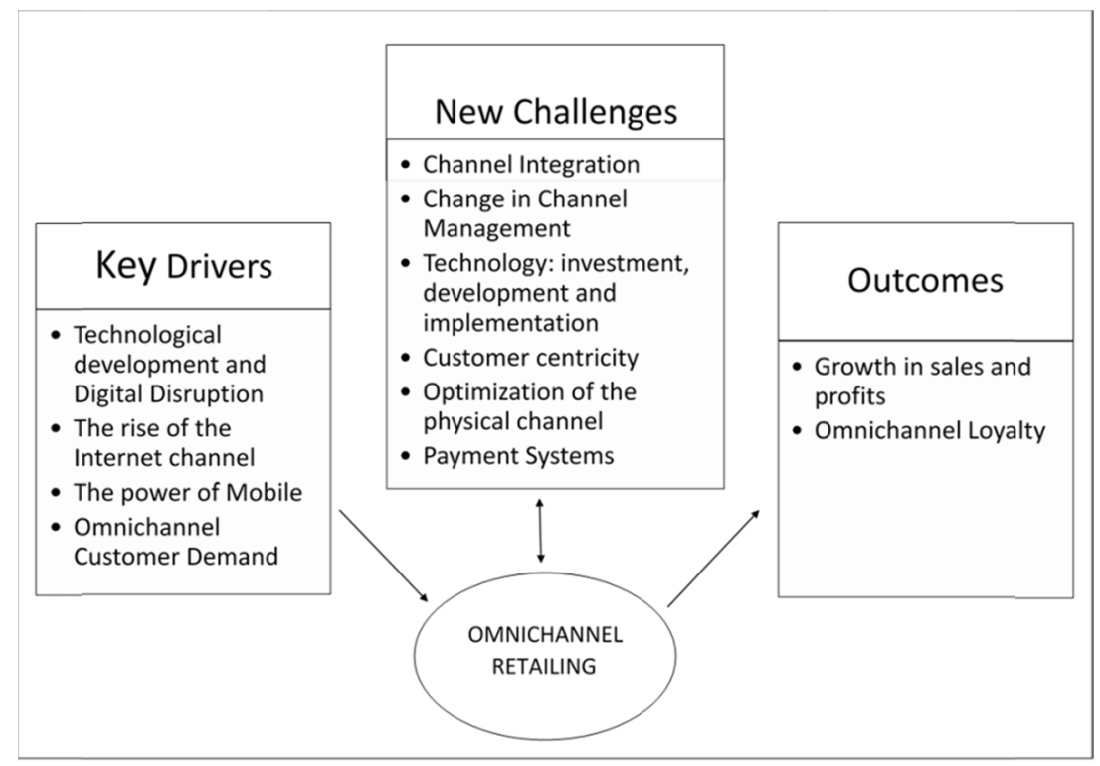

\subsection{Key Drivers of Omnichannel Retailing}

\subsubsection{Technological Development and Digital Disruption}

Omnichannel retailing is driven primarily by technology, the rise of more advanced technology allows for better 
integration of the sales channels (Oh et al., 2012). Customers have changed their shopping patterns and these changes are driven by innovative technologies, such as mobile devices, smartphones, tablets, innovative software, mobile applications, mobile payments, e-coupons, digital flyers as well as beacons, location-based services and augmented reality (Rosenblum and Kilcourse, 2013). Therefore, retailers must consider these technologies while designing their new strategies (Brynjolfsson et al., 2013; Frazer and Stiehler, 2014). All the new technological changes allow reduced cost and more access to technology in terms of collecting and analyzing big data as well as cloud computing (Rosenblum and Kilcourse, 2013). Innovations, which allow retailers to develop more effective and personalized promotion as well as price optimization, make also new in-store technologies available in addition to the mobile devices owned by the customers: virtual screens and aisles, virtual mirrors-fitting rooms, digital signage, intelligent self-service kiosks and displays, vending machines and dynamic menus, as well as QR codes and RFIDs. As a result, the retailers are trying to improve their omnichannel strategies through innovations in in-store technologies (Rosenblum and Kilcourse, 2013). Nowadays the role of in-store technologies is increasing rapidly and customers can interact in store with interactive screens as well as having experience of augmented reality. Together with all the possible changes in in-store technologies, the retailers should face another challenge as far as the physical store layout. A store redesign as well as new in-store technologies should optimize the physical store layout. New in-store technologies will be fully integrated into the shop layout in order to guarantee a much more valuable shopping experience for consumers (Rosenblum and Kilcourse, 2013). Since retailers have recognized the importance of innovative and digital technology, retailers are now investing their monetary budget in information technology as well as in mobile technology in order to improve their sales channels: mobile, online and physical channels.

Moreover, we are now entering the era of the so-called Digital Disruption. The term digital disruption indicates when a new technology produces a change in a particular task and completely changes the existing business model. The "digital disruption" literally "destroys" the "old" business models and at the same time, it rewards the new "digital forces", allowing the creation of great value for all the stakeholders. For instance, an interesting disruptive innovation is the so-called Internet of Things (IoT) defined by Xia et al. (2012) as "the networked interconnection of everyday objects, which are often equipped with ubiquitous intelligence". Simplistically, Internet of things refers to all the objects and physical things connected to the Internet. This kind of innovative connection enables access to remote sensor data, this let people control the physical world even from a distance (Kopetz, 2011). Nowadays scholars and manager are discussing about the usefulness and the role of the Internet of Things and of all the smart objects and embedded systems that are connected to the Internet. Think to the smart home that is based on the automated access control systems, as well as to the IoT-based surveillance of public places, smart passports and IoT based identifications such as the smart key to access a hotel room or a smart ski lift ticket (Kopetz, 2011). Concerning with retailing, according to existing literature, the internet of things will influence shopping behavior. Particularly, IoT will increase consumer engagement with retailers and brands (Grewal et al., 2017).

\subsubsection{The Rise of the Internet Channel in a Service Dominant Perspective}

Formerly, scholars thought that the Internet would allow the disintermediation. Somehow, this would have ousted retailers out of the market. However, over the years, the Internet has created, at the macro level, new intermediaries, once defined "infomediaries" (eg. E-bay, Amazon, Airbnb, BlaBlaCar). The Internet has, in a sense, created a new economy, the sharing economy. Actually, the integration of e-commerce and the physical channels creates opportunities for synergies that allow companies to offer different services through both different channels and different targets regarding the age groups. Internet retailing is creating greater value for the customer in terms of additional services as well as major touch-points with the company. Therefore, the Internet tends to increase the frequency of interactions between customers and retailers. In addition, the online channel can create more potential markets for established companies thanks to the potential spillover effects resulting in increased purchases in offline channels. Traditional retailers often view the Internet channel as a logical extension of the physical presence of the stores in order to complement the existing customer relationships, business processes, and distribution systems (Bernstein et al., 2008). The rise of the Internet, mobile, social networking sites and innovative technologies lead to levels of customer relationship and engagement never known before. Furthermore, customers, who prefer a variety of channel options for the process of purchasing goods and services, can reach more and more information (Verhoef et al., 2007; Chiu et al., 2011). The Internet, in fact, allows evolving from information scarcity to a condition of information democracy: more and more information about products and services are conveyed over the Internet (Sawhney and Kotler, 2001). In this way, any asymmetry of information is reduced (Amit and Zott, 2000). The customers' searching costs decrease and quick and easy checkout processes are guaranteed. From a consumer perspective, shopping 
online creates advantages in terms of time and cost savings of physical forces, as well as the ability to search and compare information (Rohm and Swaminathan, 2004). Through the online channel, retailers can offer customers access to their products twenty-four hours a day, seven days for a week, as well as a wider portfolio of goods compared to the physical channel (Agatz et al., 2008; Rigby, 2011; Webb, 2002). This allows customers to save time during their purchase process (Grewal et al., 2004). Concerning with customer experiences, online shopping allows customers to meditate and reflect, in a relaxing way, about their purchases in the comfort of their own homes (Zhang et al., 2010). Whereas, the approach to the traditional offline channels is ideal if you are looking for expert advice, if you love the touch-and-feel shopping as well as if you want to save time as far as delivery (Kollman et al., 2012). The online channel might be used to drive offline purchases, especially impulse purchases. Moreover, this trend will continue, as more consumers are familiar with online shopping.

The addition of the internet channel to the traditional portfolio of retailers can bring opportunities and challenges concerning both marketing and operations management. From a marketing perspective, the online channel provides more information to customers by reducing research costs and providing a wider range of products. However, it could cannibalize sales of existing channels. Moreover, conflicts among the several divisions that handle different channels of a company may arise. Even more among different supply chain members (Agatz et al., 2008). From an operational perspective, the integration between traditional channels and the online channel can produce synergies that reduce costs e-fulfillment. Once avoided the risk of channel conflict, companies could benefit from integrating into four major areas: lower costs, increased differentiation through value-added services, improved trust, and geographic and product market extension (Kumar et al., 2012).

Despite the many benefits that come from the adoption of the online channel, such as the opportunity to enrich the customer value proposition (Gallino and Moreno, 2014) or to prevent customer confusion and frustration (Gulati and Garino, 1999), some retailers are still reluctant to add this kind of channel. Retailers are afraid that their customers could be disappointed by the lower service level, the different price and assortment strategies that the online channel could probably offer (Verhagen and Van Dolen, 2009; Zhang et al., 2010; Kushwaha and Shankar, 2013). Other authors think of online integration as a zero-sum game, where advantages in one channel are offset by disadvantages in another channel (Falk et al., 2007).

\subsubsection{The Power of Mobile}

Smartphone dependence has become a global phenomenon. We live in a mobile world. People spent most of their daily lives on devices, with smartphones and mobile devices leading the way. Those who use a smartphone spend almost three hours per day on it (ThinkwithGoogle, 2016). Millions of customers check their smartphones constantly, day and night, whether they are spending time with family or friends, holding a business meeting or driving (Global Mobile Consumer Survey, 2015; Bellini and Aiolfi, 2017).

The growing penetration of mobile devices has significantly altered consumers' behavior and generally the way we live and work (Bellini and Aiolfi, 2017). The widespread mobile connectivity has not only changed the way we interact and communicate, but significantly influenced consumer decision-making process and consequently buying behaviors. Consumers in a retail setting use the mobile with different purposes: finding information on the web, planning the pre-shopping, creating a shopping list, comparing pricing, purchasing goods and services, engaging post-purchases activities (Shankar et al., 2010; Bellini and Aiolfi, 2017). Existing literature has considered mobile technologies a resource for helping consumers make better decisions, particularly in terms of reducing search costs and improving the quality of consumer choice (Haubl and Trifts 2000; Murray and Haubl, 2008; Sciandra, 2014; Bellini and Aiolfi, 2017).

The rapid growth of the online channel is supported by the ease of use of the internet that allows consumers greater and more efficient access, and the proliferation of internet-capable consumer electronics devices, as well as TVs, game consoles, tablet PCs and other mobile devices like smartphones. Many retailers report that already half of what they consider mobile traffic is coming through tablet devices, proved formidable drivers of traffic (Mulpuru et al., 2011). Many authors have dealt with this topic and they have conceptualized the so-called Mobile Commerce and Tablets Commerce. Consumers use both their phones, to browse the Internet and to supplement the store shopping experience, and their tablet devices to browse the web in a living room, during a bus commute to work, or at an airport (Mulpuru et al., 2011).

It is necessary that marketing managers, manufacturers and retailers manage reach their customers through the right devices, right message and the right touch point. Existing literature emphasizes the role of mobile marketing. An interesting definition of mobile marketing as "the two-way or multi-way communication and promotion of an offer between a firm and its customers using a mobile medium, device or technology" is given by Shankar and Balasubramanian (2009). Mobile marketing and all the several mobile marketing practices by 
the retailers in order to satisfy their customers' needs are becoming increasingly relevant in retailing (Shankar and Balasubramanian, 2009; Strom et al., 2014). Researchers have identified several mobile marketing practices such as mobile advertising, targeted mobile couponing, mobile emailing and messaging, mobile website creation and maintenance, mobile word of mouth marketing, mobile social networking management as well as mobile customer service (Shankar et al., 2010). Furthermore, researchers have studied the so called mobile shopping, defined by Ko et al. (2009) as "the use of the wireless Internet service for shopping activities via mobile devices" and all the factors that might influence mobile commerce and customer satisfaction (Wu and Wang, 2005; Ko et al., 2009; Lin, 2012).

A successful omnichannel strategy enables both customers and retailers to interact through multiple channels: mobile apps, social media, retailers' websites and online stores, electronic coupons, game consoles as well as smart televisions. Furthermore, other networked appliances become channels themselves (Rigby, 2011). Many retailers have realized that the mobile channel should be considered a separate channel, a sales channel as well as the physical channels able to enhance sales. Since the online channel is not enough to satisfy all the customers, retailers have started to manage the mobile, smartphone and social media channels. Retailers add the innovative channels to their traditional online and physical channels. Concerning with this new phenomenon the retailers are developing more and more mobile websites and advanced mobile apps in order to satisfy the different needs of their customers (Brynjolfsson et al., 2013). Retailers start to consider mobile applications as a valuable promotional channel, since they are not perceived as intrusive as traditional ads on mobile sites and mobile devices (Brynjolfsson et al., 2013). Furthermore, applications have a lot of potential yet to be discovered. The mobile channel has the same advantages as the online channel but there are also additional benefits associated with the nature of the smartphones. Mobile devices give the customers the possibility to blend online and offline purchasing in an innovative way: doing instant price comparisons, reading customer review and evaluating the non-digital components in the physical store (Piotrowicz and Cuthbertson, 2014).

\subsubsection{Omnichannel Customer Demand}

In the omnichannel world, people are "always on", constantly connected no matter where they are. The rise of the Internet together with the development of smartphones as well as the success of the social networking sites are the main interesting factors that have changed consumer's behavior. Consumers can now use a growing number of digital and mobile devices. Thus, they have several ways of being constantly connected. Customers are able to stay connected online with retailers all customer journey long. The omnichannel consumers are very well informed clients, who use all the channels to complete their decision-making process and purchases, anytime and anywhere, using simultaneously all the devices at their place ( $\mathrm{Pc}$, smartphones, apps, physical stores, catalogs). Thus, their customer journey is no longer linear. Moreover, the post-modern customers are very complex; they have the ability to stay constantly connected to the online-offline marketplace, which allows for easier product comparisons especially in terms of price and promotions (Brynjolfsson et al., 2013; Strang, 2013). They increasingly demand and expect to have a wide product selection available at every time and everywhere (Piotrowicz and Cuthbertson, 2014). The omnichannel consumers are always in a hurry, they have little time for shopping. However, despite the endless choice of products at their disposal, are always looking for the best price, best promotion and best service. Since consumers are different from the past, the retailers have to respond to the changing needs of their customers by offering them transparency, as well as making the shopping easy and comfortable and customizing their promotions. Above all, retailers have to create a relevant and engaging shopping experience. To create this kind of experience, the retailer has to from data and channel integration by connecting the firm with its consumers across all channels.

Inasmuch as the omnichannel consumer wants to use all channels simultaneously, retailers should fulfill an omnichannel approach that might follow customers across all channels, rather than examining channels in parallel (Gulati and Garino, 1999; Kumar et al., 2012). In an omnichannel retailing consumers might not only search for a product or comparing prices but also obtain personalized offers, book and order online goods and services, as well as make online payments, manage loyalty programs and return policies.

Since the channels are used by consumers interchangeably and constantly during searching and buying process, it becomes increasingly difficult for firms, and in some case even impossible, to control this use. Two opposing phenomena emerge when purchasing in an omnichannel context, the so-called phenomena of showrooming and webrooming. The phenomenon of showrooming can be considered as a specific form of research shopping where a buyer seeks primarily offline, and then buy online. Consumers frequently seek information in store and at the same time, also on their mobile device for more information about the offers as they can find prices more attractive (Verhoef et al., 2007). Conversely, the phenomenon of webrooming, considered in the past as a dominant form of shopping research (Brynjolfsson et al., 2013), refers to customer that research products online 
before visiting the store to purchase the product (Moran and Brightman, 2001).

\subsection{New Challenges in Implementing the Omnichannel Retailing}

\subsubsection{Opportunities and Threats of Channel Integration}

Existing literature emphasizes two basic approaches to channel integration: one is to provide access and knowledge about the Internet store at physical stores and the other is to provide access and knowledge about physical stores at the Internet store (Herhausen et al., 2015). Integration can therefore occur either from the store to the Internet or the other way around. To integrate online features into offline channels, companies provide self-service totem or assisted online terminals in their physical stores (see Louis Vuitton, Pinko and Zara). This type of integration can reduce the negative effect of non-availability for physical store customers (Bendoly et al., 2005) and complement personal service (Glushko and Tabas, 2009). Besides, to integrate offline features into their online channels, companies provide a physical store locator and information availability about their physical store assortment in their online stores (see IKEA, Carrefour, Sainsbury's and Argos). According to customers' perceptions of online integration, this integration can moderate the negative effect of non-availability for online customers (Bendoly et al., 2005).

The goal of implementing omnichannel retailing is to create a seamless shopping and customer experience by combining the benefits of both the digital and the physical retailing (Rigby, 2011; Frazer and Stiehler, 2014). Advantages related to online channel refer to price transparency, the availability of people reviews and unlimited selection of products (Rigby, 2011). Benefits related to offline retailing can be face-to-face interaction, instant gratification and a tactile product experience (Grewal et al., 2004; Agatz et al., 2008; Rigby, 2011). Consequently, an online channel can complement an offline channel, and vice versa. This has led several authors to claim that the increasing integration among channels might create benefits, namely synergies (Agatz et al, 2008; Herhausen et al., 2015; Gorsch, 2000; Steinfield and Bouwman, 2002). Customers place great value on the integration, thus a successfully implemented omnichannel strategy with a complete integration of all the channels has the potential to enhance greatly the customer shopping experience (Herhausen et al., 2015). In the omnichannel context, customers move freely between the online, mobile devices, and physical store, all within a single transaction process. Nevertheless, the journey should be regular and should provide a seamless, unified customer experience, regardless of the channels used. As channels are managed together, the perceived interaction is not with the channel, but with the brand (Rosenblum and Kilcourse, 2013). Therefore, omnichannel world is not only the expansion of channels but also the integration of client-brand-retail interactions (Neslin et al., 2014). Moreover, each customer touch point, such as brand advertising, retailer advertising, in-store communications, word-of-mouth, peer observation (seeing other customers), as well as traditional earned media, can affect the performance of retailers and brands (Baxendale et al., 2015).

Primarily, moving from a multichannel to an omnichannel strategy involves organizational changes and operational evolutions. Once the multichannel capabilities are at place, the company can make strategic decision on their operations to lead the business towards an omnichannel player. Omnichannel retailers have the opportunity to take the best practices from both brick-and-mortar and e-commerce worlds (Brynjolfsson et al., 2013). Traditional operations should be integrated with promotion, transaction management, product and pricing information management, information access, order fulfillment and customer service (McCormick et al., 2014). The first to form an omnichannel strategy was John Lewis in UK, that started the omnichannel journey in the early 2000's and they continue making enormous investments to omnichannel management and information technology systems (Savisaari, 2016).

Despite the optimistic view of channel integration, literature proposes numerous arguments to support and oppose the integration of different channels: channel integration can present both opportunities and threats to firms; namely, channel integration can be performance enhancing and performance destroying (Herhausen et al., 2015). While some scholars argue about the thesis of the complementarity of the different channels (Avery et al., 2012; Wallace et al., 2004), others believe that a channel replaces another, the so-called cannibalization among channels (Falk et al., 2007; Montoya-Weiss et al., 2003). If we focus on integration threats, some researchers assert that customer satisfaction in a channel reduces the positive assessment of the other channels because of rising expectations towards alternative channels (Falk et al., 2007). This leads to the phenomenon of cannibalization between channels. Likely, this can be accompanied by a partial reduction of sales of an offline channel because of the integration of an online channel. If the online channel, seen as a guideline, has a higher quality of service and if it is at lower risk then it may raise expectations and lower the positive assessment of the offline channel (Montoya-Weiss et al., 2003). As a result, the increase of service quality in the online channel and the consequent reduction of risks, arising from the integration of an online channel with the offline, may 
adversely affect the reactions of customers of the physical store (Herhausen et al., 2015). Conversely, if we consider integration synergies, some scholars believe that the direct and negative effect related to higher expectations for the substitute channel is offset by a stronger indirect and positive effect through improving the service experience (Wallace et al., 2004). Scholars argue that synergies could also occur when valuable brand associations, such as the highest quality service about a channel, and positive associations formed by the knowledge of a channel, like the lower risk in the online channel, can be transferred from a channel to another (Aliawadi and Keller, 2004; Kwon and Lennon, 2009). We talk about the so-called "halo effect", when the alternative channel may benefit from investments in a different channel (Wallace et al., 2004).

Literature on channel perceptions focused only on the channel level (Verhoef et al., 2007) until 2015, when Herhausen et al. (2015) explain the casual relationship between online integration, service quality perceptions of the Internet store, and customer outcomes at both retailers and channel level. Omnichannel integration not only enhances search intention, purchase intention, and willingness to pay in the Internet store but is also a source of competitive advantage for the whole firm (Herhausen et al., 2015). At the retailer level, they provide evidence that customers choose retailers that offer integrated online channels over retailers with non-integrated online channels. For the authors the service quality of the Internet store fully mediates the relationship between online integration and multichannel outcomes (Davis, 1989). Herhausen et al. (2015) provide results in favor of how online integration can lead to the creation of competitive advantages. This results in the further belief that Internet channels complement rather than cannibalize physical channels (Avery et al., 2012). Despite online integration increases the service quality of the Internet store, customers do not show lower search intention, purchase intention, and willingness to pay in the physical store (Herhausen et al., 2015). Online integration is a channel factor that increases willingness to pay across channels, it is becoming an instrument to sell products with non-digital attributes offline and online at competitive prices. Finally, Herhausen et al. (2015) affirm that the effects of online integration vary across customers with different levels of Internet shopping experience. Customers with higher levels of Internet shopping experience are less influenced by online integration (Herhausen et al., 2015). Retailers should focus online integration efforts on customer segments with lower Internet experience because these customers value integrated channels more than customer segments with high Internet experience.

Another factor at the basis of the development of omnichannel strategies is the integration of the interactive channels with traditional mass advertising channels. For instance, in an entertainment environment, mobile apps developed by a telephone company are used to interact with the users during tv shows. In the omnichannel world, the traditional division between two-way communication channels and unidirectional communication channels becomes less evident and the advertisements are integrated with interactive channels in a similar manner (Herhausen et al., 2015).

To conclude, the integration between channels is the first step toward achieving a competitive advantage that can allow retailers to survive in a context of high competition and convergence between channels. Literature tried to identify some suggestions on how to best achieve an omnichannel position according to a three-stage model: first equalize the customer experience across all channels, second link online shopping to the brick-and-mortar store, and third create delightful, personalized shopping experiences (MuleSoft). Despite the positive expectations, online integration requires a high cost investment that becomes a key question for managers who will decide whether to bear the costs or not. The possible positive effect of integration on consumer attitudes and their buying intentions suggests managers to be sure about the use of the online channel as a means of integration. Furthermore, the online might be a tool to achieve competitive advantages in the market because online integration creates much more synergies rather than cannibalization.

\subsubsection{Change in Channel Management}

Neslin et al. (2006) identified five major challenges in order to manage the multichannel environment more effectively: data integration, consumer behavior patterns, channel evaluation, allocation of resources across channels and coordination of channel strategies. For this reason, when the retailers decide to develop an omnichannel retailing approach, they should remember that the new development requires a change in the functional and operational management. A change management is defined by Sirkin et al. (2005) as "the process of continually renewing an organization's direction, structure, and capabilities to serve the ever-changing needs of external and internal customers". Literature highlights how the commitment of both senior management and employees is an important factor that determines successful outcomes of implementing an omnichannel retailing approach (Agatz et al., 2008; Webb, 2002). Many researchers suggest that channel conflicts and cannibalization can be of great concern to retailers who are arranging to increase the integration among their channels (Agatz et al., 2008). Some retailers are still reluctant to add new channels. They believe that this kind of strategy would 
move their customers from their current channel into the new one and thereby cannibalize the sales instead of increasing total sales (Webb, 2002). Channel conflicts usually arise when resources like staff, technology and capital are scarce, or when goals are incompatible (Napolitano, 2013). In this case, the efforts of the retailers to minimize inventory could result in a channel conflict about which channel should get priority of limited inventory (Kumar et al., 2012). Therefore, the inventory management will get more complex according to how many channels the retailer has established (Agatz et al., 2008; Webb, 2002).

When retailers decide to implement an omnichannel retailing they also have to manage returns in a more innovative way than before. The online return rates are much higher than the offline ones. Indeed, customers do not have the possibility of touching the product before making a purchase (Grewal et al., 2004). The omnichannel approach requires a challenge in the reverse flow of the supply chain since the customer returns an online order in store. The online assortment is wider so it is likely that the customer will return an item that normally is not present in the physical store. This means that the item must be shipped back to the warehouse because, typically, the supply chain of physical stores is not designed to handle the increased amount of returns originating from e-commerce (Savisaari, 2016). It is decisive for the retailers to determine carefully how to design the return policy, in order to find the right balance between cost efficiency and being able to offer the customers the highest service level (Bell et al., 2013). Particularly, better and clearer information on the website of the retailers has turned out to be an efficient way to decrease the number of returns of online orders. Indeed, this type of returns typically occur when the ordered item does not reflect the expectations of the customer (Min et al., 2006). If a retailer manages to design an efficient product-return system, the retailer can reach interesting advantages in terms of large cost-savings including reduced transportation, warehousing and inventory costs (Wallace et al., 2004; Gorsch, 2000). The return management is appreciated by the customers, who place great value on the convenience of the service. Since the option of buying a product online and returning it in the physical store, is a topic of great interest for the omnichannel customers (Oh et al., 2012; Bell et al., 2013; Brynjolfsson et al., 2013; Napolitano, 2013; Avensia, 2014; Cook, 2014; Piotrowicz \& Cuthbertson, 2014; Herhausen et al., 2015), many retailers are now adopting procedures of in-store return of digital purchases. This approach can be considered a way to drive customers from the digital store to the physical store (OsservatorioFedeltà Unipr, 2017).

Besides the return policy, companies have to face and manage other business activities: shipping services (click-and-collect, in-store returns of online orders and free home delivery of in-store orders), logistics (integrated inventory systems, using online returns as inventory, in-store packing of click-and-collect orders), sales tools (possibility to see content of packages, tablets as in-store sales tools), promotional activities to combine channel use (financial incentives for combining channels, consistency in pricing, store locator on website, online information of in-store availability, in-store product via QR code or app), performance measurements (tracking additional sales from click-and-collect, online statistics) and all the levers of retailing mix according to the different integrated channels (Zhang et al., 2010).

Retailers also have to decide the level of uniformity and channel integration in terms of pricing, promotions, delivery, return policies and assortment (Webb, 2002), and the maintenance of a good level of communication in order to achieve well-coordinated channels (Oh et al., 2012). Literature affirms that it is crucial for the customers not to experience inconsistencies and asymmetries among the different channels (Zhang et al., 2010). However, it is likely that retailers use special promotions as a tool to direct customers into a specific channel (Piercy, 2012). Literature argues that retailers must be aware that adding additional channels can negatively influence the existing ones if the service level of the new channel does not convey the expectations of the already existing one (Lin, 2012). At the same time a positive experience in one channel tends to carry over into the other channels and ensure the customer have a positive view of the retailer as a whole (Zhang et al., 2010).

\subsubsection{Technology: Investment, development and implementation}

Despite the emerging trends and technological changes, retailers perceive channel integration as a big challenge and some of them are restrained by a lack of consensus regarding the future of digital channels. Some retailers, indeed, believe that establishing an omnichannel strategy may increases the complexity of managing the operations and the supply chain. Concerning with the operational management, omnichannel integration requires huge investments in technologies (Herhausen et al., 2015). In order to build a successful omnichannel strategy, companies will need to involve skilled IT personnel in the reengineering of the business processes (Frazer and Stiehler, 2014). Companies should apply advanced Warehouse Management Systems (WMS) in order to keep track of the inventory at all times, and meet the customer's demand of quick and on-time deliveries (Zhang et al., 2010). This requires not only skills but also a wide financial investment (Herhausen et al., 2015). Furthermore, literature suggests that the belief that technology might not always live up to the expectations of the organization 
may drive that lack of consensus (DeSanctis and Poole, 1994). People are complex and individuals retain the same human needs and behaviors even as firms adapt new technologies (Wind and Mahajan, 2002). Despite the ability to move across channels, customers still want to see, feel, touch, and try the product, as well as to feel the shop atmosphere (Rosenblum \& Kilcourse, 2013). For this reason, it is important for retailers to make sure that the technology is well tested and developed before being implemented. In this way, customers will not experience any technical issues that might create a wall between customers and retailers. Therefore, it is important to ensure that both, the company and the market, will be receptive towards the new technology (Davis, 1989; Probert \& Shehabuddeen, 1999) because simply adopting and acquiring the newest technology might not always bring to success (Piotrowicz \& Cuthbertson, 2014). Scholars are now exploring whether the Internet of things, augmented reality as well as artificial intelligence and robots or drones will increase customer experience and consumer's engagement with retailers and brands or if they will reduce consumer's engagement as machines replace human work (the so-called machine-to-machine commerce) (Poncin \& Mimoun, 2014; Deloitte, 2016; Grewal et al., 2017; Rafaeli et al., 2017).

\subsubsection{Need for Customer Centricity}

The pioneers of omnichannel retailing built their businesses in a customer centric perspective. Indeed, omnichannel retailing is the conceptualization of a seamless consumer experience through all the available shopping channels like mobile internet devices, computers, bricks-and-mortar, television, catalog, and other several devices (Pentina and Hasty, 2009). The customer is increasingly affecting the activities of the companies, which are consequently becoming more and more customer-centric (Agatz et al, 2008). Customer centricity is a strong driver of omnichannel efforts. Retailers have to respond to the emerging needs of their omnichannel customers by offering them easy and comfortable shopping experience. Therefore, to create a relevant and engaging customer experience (Homburg et al., 2017), retailers will need to empower the channel integration by connecting the firm with its consumers across all channels. Moreover, retailers have to invest in experience, creativity and technology by focusing on their customers. Thus, the retailers, in a customer centric perspective, choose to implement an omnichannel strategy with the aims to provide the customer with a seamless integrated shopping experience as well as to create value for the customer. Conversely, in a product-centric organization the aim is only to sell products (Shah et al., 2006). Retailers and manufacturers should be able to run business according to the preferences and wishes of the customers, building a long-lasting relationship with them (Galbraith, 2011). In order to make it possible, omnichannel strategies requires a close collaboration and interaction with the customers across all contact points by providing the customers with a seamless and integrated shopping experience, from the early phase of recognition need until the final receipt of the purchases (Shah et al., 2006; Galbraith, 2011; Capgemini Consulting, 2014; McCormick et al., 2014). A satisfied customer means also achieving sustainable and long-term growth, profitability and customer loyalty (Galbraith, 2011; Ganesan et al., 200; Shah et al., 2006; Wallace et al., 2004; Selden and MacMillan, 2006). By providing the customer with a higher service level, the retailer is more likely to reach a high level of customer loyalty, with a preference for a certain retailer over its competitors (Zhang et al., 2010). Retailers might increase customer loyalty through customization, personalization (Srinivasan et al., 2002) and convenience along with a sense of community (Wind and Mahajan, 2002).

Retailers that have chosen to implement omnichannel retailing with the aim to better respond to customers' demands and to increase thereby their level of satisfaction should be able to offer their customers all possible combinations of the different channels (Zhang et al., 2010). Thus, retailers need to remove barriers within the channels and provide cross-channel and omnichannel services such as "pick-up", "click and collect", "order in-store, deliver home", "order online, return to store", "showrooms" and other combinations of online and traditional retail activities. Moreover, an omnichannel retailer must develop a personalized help from knowledgeable sales staff as well as convenient online checkout procedures (Gulati and Garino, 1999). Furthermore, retailer might guarantee the presence of Wi-Fi networks in store to communicate with customers through mobile devices and even track their behavior. Retailers could also make information on store location and in-store inventory more available and accessible from the website (Bell et al., 2014). The improved accuracy of the online information allows the customer to research the product from home and then visit the physical store to evaluate the non-digital components of the product and, if satisfied, purchase the product in-store (Verhoef et al., 2007; Rapp et al., 2015). Providing the customer with this type of information could be a successful strategy to increase store traffic (Brynjolfsson et al., 2013).

\subsubsection{Optimization of the Physical Channel}

When we talk about omnichannel retailing, we refer to the possibility for customers to order and receive goods however, wherever, and whenever they want. This becomes possible by integrating the physical and the digital 
world. Only through the fusion of digital and physical innovations, companies will be able to create the "digical" experience for their costumers (Napolitano, 2013; Giannopoulos, 2014). A digical experience is what consumers want and expect. Thus, companies have started to implement a digical strategy based on a new role of the physical store. Despite the fact that online is the only successful channel with the highest sales growth rate, $90 \%$ of all purchases are still completed in store. This is a good news for retailers because the store is still alive and performing, but they must empower their store with online and mobile in-store technologies, to improve the in-store customer experience and make their lives simpler. Innovations make new in-store technologies available so retailers start to empower their physical stores with virtual screens and aisles, virtual mirrors-fitting rooms, digital signage, intelligent self-service kiosks and displays, vending machines and dynamic menus, as well as QR codes (Rosenblum and Kilcourse, 2013). Nowadays the role of in-store technologies is increasing rapidly and customers can also experience the augmented reality. Moreover, the retailers should face another challenge concerning with the physical store layout. Retailers should optimized the physical store through store renovation and not only through the adoption of new in-store technologies. In this way, the physical store will always be relevant for both the customers and the retailers who address their investments to create a much more valuable shopping experience for their consumers. Nevertheless, its role is now evolving. For instance, omnichannel retailing reveals a great opportunity for physical stores to strengthen their role in the supply chain especially when the retailer uses the store as a mini-fulfillment center (Napolitano, 2013; Giannopoulos, 2014). The physical store is used as an additional distribution and storage facility where the customer can pick up online orders or where the retailers can ship online orders straight from the store to the customer (Napolitano, 2013). Concerning with this perspective, the fulfillment center can vary in size depending on the needs of the retailer and the capacity of the physical store (Agatz et al., 2008). Literature suggests that using the physical stores as mini-fulfillment centers has several advantages. The mini-fulfillment center makes the use of physical shops more productive in order to better serve online sales and provide customer with the opportunity to pick up at the store. It also allows the retailer to reduce costs in terms of product delivery, which plays a relatively expensive role for the retailer (Napolitano, 2013). Additionally, the use of in-store pickup allows the retailer to exploit its existing inventory providing real-time information about inventory availability (Giannopoulos, 2014). Thereby the excess stock, that otherwise risks to be sold at a reduced price, should decrease (Zhang et al., 2010). Furthermore, if the customers pick up in store and bring the merchandise home there could be a potential advantage related to the opportunity to increase store traffic and achieve additional sales (Gao and Su, 2016). Therefore, the opportunity of buying online and picking up in store enables retailers to reach new customers. However regarding to the existing customers, the shift from online fulfillment to store fulfillment may decrease profit margins, when the latter is less cost effective (Gao and $\mathrm{Su}, 2016$ ).

Many retailers have recently started to offer their customers the opportunity to buy online and pick up in store. As far as the grocery sector, major grocery stores from the early 2000's have tried to implement the fulfilment processes by picking from a centralized warehouse, or by picking from a convenient existing store (Banjo and FitzGerald, 2014). One of the first mover was the grocery chain Waitrose in 2002. Their model was to pick, pack and deliver to customers' homes from their centralized and very sophisticated fulfillment center. Afterwards Macy's Inc started to rethink its brick-and-mortar stores by transforming them into mini-fulfillment centers in order to serve better online sales and make the use of the physical shops more productive (Rosenblum and Kilcourse, 2013). Nowadays some grocery retailers such as Leclerc and Auchan in France start to build new "solo" stores, a warehouse where the retailer picked up goods and the customer drives to it in their car to collect their goods. These strategies are known as "Click and Drive" in France or as "Click and Collect" in the UK where grocery retailers such as ASDA, Tesco and Sainsbury's have added this operational process in their marketing strategies.

The future role of the physical store is not clear, also because the type of shopping, utilitarian or hedonic, could influence the motivation to use online or traditional channels (Planet Retail, $2016 \mathrm{~b}$ ). Nevertheless, recent researches state that $72 \%$ of European consumers still make most or all of their shopping in a store (iVend Retail, 2015). The rising omnichannel shopping has strengthened bricks-and-mortar stores, the only places where consumers can see, touch and experience products before purchasing.

\subsubsection{Advanced Payment Systems}

The rise of the Internet and mobile have encouraged customers to move, in an omnichannel environment, from traditional physical channels to the digital ones. The dynamic demand and changing preferences of customers, along with financial technology innovations have given rise to digital channels such as Internet banking. The adoption of technology in financial services has transformed the financial sectors as well as banking business models and financial institutions. Moreover, the current shift to the omnichannel paradigm has led to the 
so-called mobile banking in the digital era, which has brought opportunities and challenges for banks and financial institutions (McKinsey, 2014). Therefore, in order to create value for customers, banks are now creating innovative financial products along with empowered distribution channels like credit cards, enriched with innovative features, and mobile payments. Particularly, since mobile commerce increases in popularity the mobile payment system (m-payment) has emerged (Kim et al., 2010). Mobile payment is defined as any payment in which a mobile device is utilized to initiate, authorize, and confirm a commercial transaction (Au \& Kauffman, 2008). Since mobile payments refer to payment processes performed via mobile devices, they are a natural evolution of electronic payment that enable convenient mobile commerce transactions (Mallat, 2007). Therefore, the digitalization of services and payments has enhanced transaction performance. Particularly, mobile payments, made with smartphones, eliminate the need for physical credit card payment infrastructure. Customers can pay for goods and services using their mobile devices and wireless communication technologies. People using their mobile devices are able to connect to a server, perform authentication and authorization and finally make their mobile payments and receive confirm of the completed transaction process.

Scholars have always debated whether mobile payments differ from other forms of payments. Concerning with the function of mobile payments, all researchers' definitions refer to the transfer of monetary value. Conversely, different opinions can be found regarding the phases of the payment process. Some authors include the authorization and initiation of the payment in their definition of payment process (Henkel, 2002) while other researchers also include the execution of the payment (Dahlberg et al., 2008). Along with the mobile payment system, Bachfischer and Lawrence (2006) have developed a user-orientated taxonomy of mobile payment systems by classifying existing mobile payment systems on a set of consumer-oriented criteria such as simplicity, security, and costs. Moreover, the mobile user's intention to use mobile payment has always interested researchers as well as financial institutions and payment service providers, which can benefit from enhanced understanding of the key factors at the basis of users' intention towards mobile payments.

Despite many firms have already adopted mobile payment options, there is still a lack of acceptance of mobile payment services among customers whit, apparently, still few consumers who choose this alternative form of payment (Schierz et al, 2010). Nevertheless, consumers are aware of mobile payments and they are beginning to use mobile payments as an extension of credit or debit cards, rather than as a substitute for cash. One possible cause of the low adoption of mobile payments may refer to consumers' fear for their privacy and mobile security as well as threat of fraud. However, nowadays, technology advances and mobile security are supporting the emergence of mobile payments by reducing threats of risk and frauds. Firms have already invested in security and authentication through the implementation of rigorous technology standards for customer authentication, such as two-factor authentication, and secure payments (Capgemini, 2017). For instance, IBM has announced its new IBM Z mainframe that allows encrypted transactions by credit card in order to reduce the probability of cyberattacks (Capgemini, 2017).

Concerning with the retailers' perspective, mobile payments will become a critical and crucial topic in their overall marketing strategies. Mobile payments have evolved from being a simple transaction utility to a tool to increase sales and to improve customer engagement. Many retailers are already developing mobile technology and mobile payments in their stores with the aim to create an engaging omnichannel experience. Moreover, it can also help them to increase customer loyalty along with the possibility to acquire new customers by offering promotions that are more relevant and personalized thanks to data collected from mobile payments. Retailers have to face these new challenges of alternative form of payment by adopting advanced technologies as well as contactless technology and other advanced payments systems in order to stimulate and to improve more effectively consumer's use intention. Retailers could improve perceived benefits and perceived security only by increasing user trust and decreasing perceived risk about mobile and e-payment systems (Pei et al., 2017).

Several successful mobile payment systems have already been developed in Asia, particularly in China, Japan and South Korea, while in Europe and North America, the development of mobile payments has not been as successful as in Asian countries. Mobile payments solutions have the highest market share in China with Chinese mobile payments transaction value estimated to reach $¥ 12.2$ trillion (US\$1.83 trillion) in 2016 , up from $¥ 0.2$ trillion (US\$31.7 million) in 2012 (iResearch, 2017). The ubiquity of mobile Internet along with evolving consumer preferences and advanced infrastructure are the forces that are guiding the success of the mobile payments in China (iResearch, 2017). Popular Chinese payment services rely mainly on two mobile payments technologies: NFC technology (near-field communication) and QR code. NFC technology includes PayPal, Apple Pay (developed by Apple and rolled out in China in 2016), Huawei Pay and Samsung Pay. Otherwise, QR-based payment services include WeChat Pay (launched by Tencent in 2014), Alipay (used on Taobao, Tmall and Alibaba websites) and Baidu Wallet (launched by Baidu in 2014). 
Mobile wallets are quickly becoming the norm, particularly among millennials. Particularly, e-wallets, mobile wallets or digital wallets are used to initiate mobile payments. Indeed, a digital wallet enables customers to store their credit card information in a mobile app instead of on a plastic card and then to make purchases through the mobile app, faster than using traditional swipe credit cards. Mobile wallets are perceived by consumers as more convenient thanks to a better user interface and the possibility for customers to store coupons and loyalty card information. The use of NFC technology and mobile wallets among consumers will continue in the next years as well as the rise of the emerging payment instrument of bitcoin and the resulting development of Bitcoin exchange platforms, which manage transactions through these wallets (Coindesk 2016).

Alibaba, in China, has recently developed an interesting innovative payment method called "Smile to pay", in partnership with Alipay, through which people can pay with their face. Thanks to "Smile to pay", it is possible to transfer money through Alipay app using only individuals' face as credentials. The new payment solution develop by Alibaba employs facial recognition in secure financial transactions thanks to an artificial-intelligence technique that is especially effective for image recognition that will most reliably identify a person. Along with face-detecting payment systems, KFC restaurant in Hangzhou, is testing an innovative facial recognition payment system that lets customers pay for their meal by smiling at a camera. Therefore, Chinese players use face-detecting systems to authorize payments as well as provide access to facilities, and track down criminals.

\subsection{The Potential Outcomes Coming from the Adoption of an Omnichannel Retailing Approach:}

\subsubsection{Growth in Sales and Profits}

Essentially, most of the retailers choose to adopt an omnichannel strategy to reach higher profits through increased sales and more efficient operations (Wallace et al., 2004). Behind their decisions there is the belief that multichannel shoppers are often more valuable and profitable than customers using only one channel. The amount is even higher for the omnichannel customers. With the increasing amount of the possible combinations of channels and services, accessible and available to customers, retailers will be able to meet different customer demands (Ward, 2001). Moreover, one of the positive outcomes arising from the adoption of an omnichannel retailing approach relates to the possibility of reaching new customers through the provision of online services. Reaching new customers might result in increasing purchases and reducing costs for new channels (Mulpuru et al., 2011). Thus, the omnichannel approach leads to an increase in sales and profits (Brynjolfsson et al., 2013). Implementing an omnichannel strategy also allows the retailers to expose customers to new products that they otherwise might not have been exposed to (Rigby, 2011; Lewis et al., 2014). As far as this perspective, literature highlights the potential of the omnichannel retailing in terms of increased sales. Researches and balance sheet data analysis confirm the hypothesis that retailers could increase their profits by integrating the online and offline channels, rather than having a channel that competes with another one (Baxter and Vater, 2014).

\subsubsection{Omnichannel Loyalty}

Since consumers switch between several devices when shopping, retailers have to provide their customers seamless offline-online experiences. In an omnichannel environment, retailers need to combine all the different touchpoints through several "interweaving solutions" so that consumers can easily go from one touchpoint to another with a seamless omnichannel experiences (Picot-Coupey et al., 2017). Primarily, retailers will need to understand the value of the shoppers across all channels in order to improve customer loyalty in a competitive retail environment. Understanding online customer loyalty is easier than in a physical store because when customers $\log$ in, retailers can see their previous activities, and offer to customers targeted promotions and incentives based on their buying preferences, especially in terms of how frequently they visit the site and how great is the value of the purchases they make online. This is not always possible inside the store. Retailer thanks to big data are able to understand lifetime customer value and therefore reward consumers based upon it. This is the key to establish a long-lasting relationship with the customers. Omnichannel retailers will need to have an omnichannel vision of all their customers; this could be possible only by monitoring all customers' purchasing activities both online and offline. In this way, retailers might increase the relevance of their marketing strategies and create additional value for both the entire firm and its customers. Omnichannel retailers want not only to sell products to their loyal consumers. They also wish to engage, retain and grow new customers and make them satisfied and loyal to the firm.

Researchers argue that customer satisfaction as well as a positive experience with a touchpoint could be significant antecedents of customer loyalty (Anderson and Sullivan, 1993; Homburg and Giering, 2001; Shankar et al., 2003; Ieva and Ziliani, 2017). Loyalty is defined as repeated purchase behavior and probability of product repurchase by Lipstein (1959) and McConnell (1968). Since there is a strong positive relationship between customer satisfaction and loyalty, retailers will need to achieve high levels of customer satisfaction. In an 
omnichannel perspective, retailers will need to combine all the different touchpoints in order to reach highly loyal customers. Thanks to their digital nature, digital touch points allow for a better customer experience as well as advanced customer data collections (Ieva and Ziliani, 2017).

Literature has opened innovative search directions concerning with the customer loyalty. Particularly, scholars are discussing the evolution of customer loyalty towards omnichannel loyalty. Omnichannel loyalty can be considered as the integration of physical and digital loyalty marketing in order to face the challenges created by new players and new consumers. An Omnichannel loyalty program allows retailers to engage new customers to the loyalty program through their digital devices before, during and after the interaction in store. Moreover, it allows loyal customers to move inside a "authenticated" space where each activity before, during and after the purchase is perceived as relevant because personalized and seamless (OsservatorioFedeltà Unipr, 2017). Compared to traditional loyalty programs, omnichannel loyalty is defined by Hemsey (2012) as "the approach to maximizing cross-channel marketing with an emphasis on driving cumulative loyalty-related outcomes not through a single campaign, but through a lifetime of ongoing campaigns that speak to that customer and engage them within the brand". Actually, the only way to establish customer loyalty as well as a long-lasting relationship is by offering channel-optimized loyalty programs. This is why, omnichannel loyalty programs aim to provide a seamless marketing experience across all channels by delivering loyalty from the very beginning of the customer lifecycle and by engaging customers with the right content at the right time on the right channel (Hemsey, 2012).

Retailers and producer will need to restructure their loyalty and rewards programs efficiently in order to create omnichannel loyalty by engaging and retaining customers. Therefore, omnichannel loyalty programs need to be incorporated throughout the entire path-to-purchase. Before integrating and implementing an omnichannel loyalty program, retailers and producers will need to collect customer data through customer relationship management (CRM) and take care of their existing multichannel loyalty efforts. When retailers decide to adapt an omnichannel loyalty program they will need to engage customers across different channels and reward them for their purchasing activities. Moreover, retailer will need to address customers with personalized offers based on their individual preferences and purchase history. Mobile (such as smartphones and mobile customer loyalty cards), social media, direct mail and in-store devices are the most relevant touchpoints used to address customers directly (Hemsey, 2012). Since the mobile has become such important tool throughout the entire pat-to-purchase, the most effective way to develop an omnichannel loyalty strategy is to use the mobile in both digital and physical stores. Retailer will need to stay connected with consumers via social media as well as mobile technologies, without forgetting to incorporate the human touch.

Successful omnichannel retailing and omnichannel loyalty enable retailers to engage omnichannel customers during the entire customer journey. In this way, retailers can have a 360-degree view of their customers as well as the possibility to guide customers through multiple channels simultaneously. Finally, a truly omnichannel marketing strategy will increase customer engagement and loyalty to the retailers, with omnichannel customers that spend $15 \%$ to $30 \%$ above multichannel customers (Parker and Hand, 2009).

\section{Conclusion, Limitations and Future Researches}

The advent of the internet, mobile technologies and increasing technological innovations have changed the retail world. Online channel has become a "key channel" for selling products and services. The proliferation of channels and touch points has affected not only consumer behavior but also companies' business models. Many retailers have started to develop multichannel and omnichannel strategies by adding new channels through which interact with the consumers. We are now moving to a world increasingly omnichannel. Omnichannel retailing is the conceptualization of the complete integration of all channels (Rigby, 2011; Klosek, 2012; Frazer and Stiehler, 2014). There is no distinction between the online channel and the physical one. When retailers decide to move towards an omnichannel strategy have to face relevant challenges and revise their competitive strategies (Brynjolfsson et al., 2013). The topic becomes more relevant as technological developments continue to disrupt retail strategies and managers are worried about how to manage the several touch points and channels simultaneously available to customers.

Our research attempts to explain how literature and business models are moving from multichannel retailing towards the implementation of omnichannel strategies. We have followed a blended approach based on literature review, theoretical background as well as some interesting insights resulting from business' case histories. To address the concerns of managers and retailers about the new challenges they will need to face in implementing an omnichannel retailing approach, we have presented a theoretical framework, concerning with the adoption of the omnichannel strategies in the overall marketing strategies, built on insights and managerial implications 
coming from our own literature overview. Key drivers, new challenges and the potential outcomes of the adoption of the omnichannel retailing are explained in our theoretical framework in order to help managers and practitioners who might decide to enter the omnichannel retailing. To deal with the topic we have started from three research questions that have guided our literature review as well as our theoretical framework. We have investigated what are the key drivers that have stimulated retailers to develop an omnichannel retailing strategy (Q1), what are the new challenges that retailers will need to face when they decide to implement an omnichannel strategy in their overall marketing strategy (Q2) and finally what are the potential outcomes of a correct and successful implementation of an omnichannel retailing strategy (Q3). We have tried to figure out interesting answers to our research questions by analyzing the existing literature and retailers' case histories. Our results are displayed synthetically in the framework proposed in Figure 1.

We have identified four key drivers that have stimulated retailers to implement an omnichannel strategy in their overall marketing strategy (Q1). Omnichannel retailing is driven primarily by technology that allows for a deeper integration of the sales channels. The innovative technologies reduce costs, allow more access to information and big data and finally enable retailers to develop more effective and targeted promotion. Along with the digital disruption, retailers have recognized the importance of innovative and digital technology, investing their budget in information technology, mobile technology as well as in in-store technology. Moreover, the rise of the internet channel in a service dominant perspective has created opportunities for the integration of the online channels and the physical ones. Internet retailing allows companies to create greater value for the customer in terms of additional services as well as major touch-points with the company by offering different services through different channels. The rise of the Internet, mobile, social networking sites and innovative technologies lead to levels of customer relationship and engagement never known before. The Internet, in fact, allows evolving from information scarcity to a condition of information democracy (Sawhney and Kotler, 2001). Therefore, the online channel can create more potential markets for established companies thanks to the potential spillover effects resulting in increased purchases in offline channels (Bernstein et al., 2008). An interesting key factor that has encouraged retailers to develop an omnichannel strategy is the power of mobile. The growing penetration of mobile devices and the resulting smartphone dependence have significantly changed consumers' behavior and generally the way individuals live and work (Bellini and Aiolfi, 2017). The widespread mobile connectivity has not only altered the way we interact and communicate, but significantly influenced consumer decision-making process and consequently buying behaviors. Since retailers have realized that the mobile channel should be considered a sales channel, as well as the physical channels, they have started to manage the mobile, smartphone and social media channels with the aim to satisfy the different needs of their customers. Retailers have added the innovative channels to their traditional online and physical channel by developing more and more mobile websites and advanced mobile apps. Finally, on consumers' perspective, the new omnichannel customer drives omnichannel retailing. We live in an omnichannel world where people are always on. Consumers have several ways of being constantly connected. Particularly they are able to stay connected with retailers all customer journey long. The omnichannel consumers are very complex but very well informed customers. They use all the channels simultaneously and their customer journey is no longer linear. Since consumers are different from the past and omnichannel customers use the channels interchangeably during searching and buying process, retailers will need to adopt an omnichannel approach that might follow customers across all channels by creating a seamless shopping experience.

Once analyzed the main factors that have driven the retailer to adopt a multi and omnichannel approach, we tried to understand what might be the new challenges that retailers will need to face when they decide to implement an omnichannel strategy in their overall marketing strategy (Q2). According to existing literature, the goal of implementing omnichannel retailing is to create a seamless shopping and customer experience by combining the benefits of both the digital and the physical retailing (Rigby, 2011; Frazer and Stiehler, 2014). Consequently, retailers will need to manage the channel integration. Integration can occur either from the store to the Internet or the other way around. The integration between online and offline channels creates much more synergies rather than cannibalization and it is the first step toward achieving a competitive. However, despite the positive expectations, channel integration requires a high cost investment that becomes a key question for managers who will decide whether to bear the costs or not. Furthermore, moving from a multichannel to an omnichannel strategy involves organizational changes and operational evolutions concerning with the supply chain. Companies will need to face and manage several business activities: shipping services, logistics, sales tools, return policies, promotional activities to combine channel use, performance measurements, levers of retailing mix (Zhang et al., 2010). Along with the organizational changes, omnichannel retailing requires huge investments in technology. Thus, retailers will need to involve skilled IT personnel in the reengineering of their business processes (Frazer and Stiehler, 2014). Therefore, it is important to ensure that both, retailers and the 
market are receptive towards the new technology. Moreover, technology has to be well tested and well developed before being implemented. In this way, customers will not experience any technical issues. Furthermore, an omnichannel approach together with the implementation of innovative technologies in store allow retailers to optimize the physical channel. The physical store is still alive and performing. However, retailers will need to empower their store with online and mobile technologies in-store. Innovations has made new in-store technologies available: virtual screens, virtual mirrors-fitting rooms, digital signage, intelligent self-service kiosks and displays, vending machines and dynamic menus, QR codes, RFID technologies as well as augmented reality (Rosenblum and Kilcourse, 2013). Retailers will also need to optimize the physical store through store renovation. In this way, the physical store will always be relevant for both the omnichannel consumers and the retailers who address their investments to create a much more valuable shopping experience for their customers. Indeed, retailers have chosen to implement omnichannel retailing with the aim to respond better to customers' demands and to increase thereby their level of satisfaction. Retailers in an omnichannel world will need to build their business in a customer centric perspective. In order to respond to the emerging needs of their omnichannel customers, retailers should be able to offer their customers all possible combinations of the different channels. Thus, omnichannel retailers, in a customer centric perspective, will need to provide the customer with a relevant, engaging and seamless integrated shopping experience. Furthermore, in an omnichannel world, customers can pay for goods and services using their mobile devices and wireless communication technologies. The rise of the Internet and mobile have encouraged customers to move from traditional payment systems to more advanced payment methods. Consumers are aware of mobile payments and they are beginning to use mobile payments as an extension of credit or debit cards, rather than as a substitute for cash. Therefore, retailers will need to develop advanced mobile technology as well as contactless technology and mobile payments in their stores in order to create an engaging omnichannel experience and increase customer loyalty.

Finally, we have tried to summarize the potential benefits and outcomes resulting from the adoption of an omnichannel retailing in two macro areas: growth in sales and profits and the establishment of omnichannel loyalty and a long-lasting relationship with the customers (Q3). Implementing an omnichannel strategy allows the retailers to reach higher profits, through increased sales and operations that are more efficient. Furthermore, omnichannel retailers will be able to meet different customer demands through the provision of online services. Therefore, the omnichannel approach enables retailer to reach new customers as well as to increase purchases and reduce costs for new channels (Mulpuru et al., 2012). Since customer centricity is a strong driver of omnichannel efforts, retailers will need to combine all the different touchpoints in order to reach highly loyal customers. This is why innovative retailers will need to restructure their loyalty and rewards programs with the aim to create omnichannel loyalty by engaging and retaining customers. A successful omnichannel retailing approach will be able to create the so-called omnichannel loyalty. Successful omnichannel retailers will be able to engage their omnichannel customers during the entire customer journey by addressing the right message through the right touchpoint to the right audience. A successful omnichannel strategy will result in long-term omnichannel customer loyalty with the possibility for the retailers to have a 360 -degree view of their omnichannel and loyal customers.

We believe that managers can get some useful insights for their future strategies by looking at our results and theoretical framework. Managers should take in account our framework when they decide to develop an omnichannel strategy. A successful implementation of an omnichannel strategy might enables managers to address better their marketing efforts and capture the goodwill of consumers by increasing the engagement of the customers and creating a long lasting relationship with them.

While our research has valuable contributions, it also has some limitations. Limitations are associated with the qualitative methodology through which we conducted the research. Therefore, we tried to figure out a theoretical framework that is not generalizable. Our study, however, wants to be a useful investigation about the rise of the new paradigm of the omnichannel retailing. It is just a first step, which has opened considerable opportunity for our ongoing research on omnichannel retailing.

Future research will explore the omnichannel paradigm by considering factors not contemplated in our theoretical framework as well as new emerging challenges that omnichannel retailers will need to face over next years. Some existing challenges might become key drivers or potential outcomes while the latter might be new challenges or might evolve in key drivers of omnichannel retailing. Furthermore, we promise to test our theoretical framework with a quantitative analysis. Moreover, it will be interesting to decline the omnichannel approach according to different areas of retail. For instance, it might be interesting to have a more sectoral focus on the fashion retailing as well as on grocery retailing, considered a high potential retail sector.

Researchers suggest that the online grocery sales are set to accelerate over the next five years, with the online 
grocery forecast to gain $0.9 \%$ between 2016 and 2021, compared to $0.4 \%$ percentage points of share 2011-2016 (Planet Retail, 2016 b). Online grocery is strongest in Europe. Euro zone is the most developed online grocery region (online grocery will account for $2.1 \%$ of food retail format sales by 2021, Planet Retail 2016 b), thanks to the success of players as Tesco.com and Ocado in the UK or Auchan and Carrefour in France. After Europe, follow the Asia and Oceania (1.8\%) that is experiencing a rapid growth especially in China, then North America (1.5\%), Latina America (0.5\%) and finally Africa and Middle East (0.2\%) (Planet Retail, 2016 b). Grocery retail market is currently facing the digitization process that has already revolutionized the world of publishing, editorial, books, electronics and apparel. Over the next years, many grocery retailers will invest into omnichannel management as well as into the integration of in-store and online operations.

\section{References}

Agatz, N. A., Fleischmann, M., \& Van Nunen, J. A. (2008). E-fulfillment and multi-channel distribution-A review. European Journal of Operational Research, 187(2), 339-356. https://doi.org/10.1016/j.ejor.2007.04.024

Ailawadi, K. L., \& Keller, K. L. (2004). Understanding retail branding: conceptual insights and research priorities. Journal of Retailing, 80(4), 331-342. https://doi.org/10.1016/j.jretai.2004.10.008

Amazon. (2017). Amazon.com official website, visited in April 2017

Amit, R., \& Zott, C. (2000). Value drivers of e-commerce business models (No. 2000-2006). Fontainebleau: INSEAD.

Anderson, E. W., \& Sullivan, M. W. (1993). The antecedents and consequences of customer satisfaction for firms. Marketing Science, 12(2), 125-143. https://doi.org/10.1287/mksc.12.2.125

Ansari, A., Mela, C. F., \& Neslin, S. A. (2008). Customer channel migration. Journal of Marketing Research, 45(1), 60-76. https://doi.org/10.1509/jmkr.45.1.60

Au, Y. A., \& Kauffman, R. J. (2008). The economics of mobile payments: Understanding stakeholder issues for an emerging financial technology application. Electronic Commerce research and Applications, 7, 141-164. https://doi.org/10.1016/j.elerap.2006.12.004

Avensia (2014) Omni-channel Retail 2014. Avensia AB. Banjo and Fitzgerald.

Avery, J., Steenburgh, T. J., Deighton, J., \& Caravella, M. (2012). Adding bricks to clicks: Predicting the patterns of cross-channel elasticities over time. Journal of Marketing, 76(3), 96-111. https://doi.org/10.1509/jm.09.0081

Bachfischer, A., \& Lawrence, E. M. (2006). Implementation models in mobile payments. In IASTED International Conference on Advances in Computer Science and Technology. Acta Press Anaheim. http://hdl.handle.net/10453/1968

Banjo, S., \& Drew, F. G. (2014). Stores confront new world of reduced shopper traffic.

Baxendale, S., Macdonald, E. K., \& Wilson, H. N. (2015). The impact of different touchpoints on brand consideration. Journal of Retailing, 91(2), 235-253. https://doi.org/10.1016/j.jretai.2014.12.008

Baxter, M., \& Vater, D. (2014). Building the retail bank of the future. Bain \& Company.

Beck, N., \& Rygl, D. (2015). Categorization of multiple channel retailing in Multi-, Cross-, and Omni-Channel Retailing for retailers and retailing. Journal of Retailing and Consumer Services, 27, 170-178. https://doi.org/10.1016/j.jretconser.2015.08.001

Bell, D. R., Gallino, S., \& Moreno, A. (2013). Inventory showrooms and customer migration in omni-channel retail: The effect of product information. http://dx.doi.org/10.2139/ssrn.2370535

Bellini, S., \& Aiolfi, S. (2017). The impact of mobile device use on shopper behaviour in store: An empirical research on grocery retailing. International Business Research, 10(4), 58. https://doi.org/10.5539/ibr.v10n4p58

Bendoly, E., Blocher, J. D., Bretthauer, K. M., Krishnan, S., \& Venkataramanan, M. A. (2005). Online/in-store integration and customer retention. Journal of Service Research, 7(4), 313-327. https://doi.org/10.1177/1094670504273964

Bernstein, F., Song, J. S., \& Zheng, X. (2008). "Bricks-and-mortar" vs.“clicks-and-mortar": An equilibrium analysis. European Journal of Operational Research, 187(3), 671-690. https://doi.org/10.1016/j.ejor.2006.04.047 
Blattberg, R. C., Kim, B. D., \& Neslin, S. A. (2008). Why database marketing?. In Database Marketing (pp. 13-46). Springer New York. https://doi.org/10.1007/978-0-387-72579-6_2

Brynjolfsson, E., Hu, Y. J., \& Rahman, M. S. (2013). Competing in the age of omnichannel retailing. Mit Sloan Management Review, 54(4), 23.

Kim, C., Mirusmonov, M., \&Lee, I. (2010). An empirical examination of factors influencing the intention to use mobile payment. Computers in Human Behavior, 26(3), 310-322. https://doi.org/10.1016/j.chb.2009.10.013

Capgemini Consulting. (2014). Are you ready? How to create an always-on, always-open shopping experience. Capgemini Consulting.

Capgemini Consulting. (2017). Top 10 trends in payments. Capgemini Consulting.

Chiu, H. C., Hsieh, Y. C., Roan, J., Tseng, K. J., \& Hsieh, J. K. (2011). The challenge for multichannel services: Cross-channel free-riding behavior. Electronic Commerce Research and Applications, 10(2), 268-277. https://doi.org/10.1016/j.elerap.2010.07.002

Coindesk. (2016). State of Bitcoin and Blockchain 2016. Ilford, Essex, UK.

Cook, G. (2014). Customer experience in the omni-channel world and the challenges and opportunities this presents. Journal of Direct, Data and Digital Marketing Practice, 15(4), 262-266. https://doi.org/10.1057/dddmp.2014.16

Coupey-Picot, K., Hure, E., \& Michaud-Trevinal A. (2017). Omni-channel retailing: exploring how retailers interweave touchpoints and reconsider their store design. In proceedings of EAERCD conference 2017, Dublin.

Dahlberg, T., Mallat, N., Ondrus, J., \& Zmijewska, A. (2008). Past, present and future of mobile payments research: A literature review. Electronic Commerce Research and Applications, 7(2), 165-181. https://doi.org/10.1016/j.elerap.2007.02.001

Davis, F. D. (1989). Perceived usefulness, perceived ease of use, and user acceptance of information technology. MIS quarterly, 319-340. https://doi.org/10.2307/249008

Deleersnyder, B., Geyskens, I., Gielens, K., \& Dekimpe, M. G. (2002). How cannibalistic is the Internet channel? A study of the newspaper industry in the United Kingdom and the Netherlands. International Journal of Research in Marketing, 19(4), 337-348. https://doi.org/10.1016/S0167-8116(02)00099-X

Deloitte, 2016; Deloitte; Retail Trends in 2016. (2016) (accessed December 12, 2016), [https://www2.deloitte.com/uk/en/pages/consumer-business/articles/retail-trends-2016.html].

DeSanctis, G., \& Poole, M. S. (1994). Capturing the complexity in advanced technology use: Adaptive structuration theory. Organization science, 5(2), 121-147. https://doi.org/10.1287/orsc.5.2.121

Fairchild, A. M. (2014). Extending the network: Defining product delivery partnering preferences for omni-channel commerce. Procedia Technology, 16, 447-451. https://doi.org/10.1016/j.protcy.2014.10.111

Falk, T., Schepers, J., Hammerschmidt, M., \& Bauer, H. H. (2007). Identifying cross-channel dissynergies for multichannel service providers. Journal of Service Research, 10(2), 143-160. https://doi.org/10.1177/1094670507306683

Frazer, M., \& Stiehler, B. E. (2014, January). Omnichannel retailing: The merging of the online and off-line environment. In Global Conference on Business \& Finance Proceedings (Vol. 9, No. 1, p. 655). Institute for Business \& Finance Research.

Galbraith, Jay R. (2011). Designing the customer-centric organization: A guide to strategy, structure, and process. John Wiley \& Sons.

Gallino, S., \& Moreno, A. (2014). Integration of online and offline channels in retail: The impact of sharing reliable inventory availability information. Management Science, 60(6), 1434-1451. https://doi.org/10.1287/mnsc.2014.1951

Ganesan, S., George, M., Jap, S., Palmatier, R. W., \& Weitz, B. (2009). Supply chain management and retailer performance: emerging trends, issues, and implications for research and practice. Journal of Retailing, 85(1), 84-94. https://doi.org/10.1016/j.jretai.2008.12.001

Gao, Fei, \& Xuanming Su. (2016). Omnichannel Retail Operations with Buy-Online-and-Pick-up-in-Store. Management Science. https://doi.org/10.1287/mnsc.2016.2473 
Gensler, S., Leeflang, P., \& Skiera, B. (2012). Impact of online channel use on customer revenues and costs to serve: Considering product portfolios and self-selection. International Journal of Research in Marketing, 29(2), 192-201. https://doi.org/10.1016/j.ijresmar.2011.09.004

Geyskens, I., Gielens, K., \& Dekimpe, M. G. (2002). The market valuation of internet channel additions. Journal of marketing, 66(2), 102-119. https://doi.org/10.1509/jmkg.66.2.102.18478

Giannopoulos N. (2014). Converting stores to fulfillment centres. Moving beyond the traditional store. Retail Info Systems News, March/April, 23-25.

Global Mobile Consumer Survey, 2015.

Glushko, R. J., \& Tabas, L. (2009). Designing service systems by bridging the "front stage" and "back stage". Information Systems and E-Business Management, 407-427. https://doi.org/10.1007/s10257-008-0106-0

Gorsch, D. (2000). The impact of hybrid channel structures on the customer purchase process: A research outline. https://doi.org/10.1.1.26.4354

Grewal, D., Iyer, G. R., \& Levy, M. (2004). Internet retailing: enablers, limiters and market consequences. Journal of Business Research, 57(7), 703-713. https://doi.org/10.1016/S0148-2963(02)00348-X

Grewal, D., Levy, M., \& Kumar, V. (2009). Customer experience management in retailing: an organizing framework. Journal of retailing, 85(1), 1-14. https://doi.org/10.1016/j.jretai.2009.01.001

Grewal, D., Roggeveen, A. L., \& Nordfält, J. (2017). The future of retailing. Journal of Retailing, 93(1), 1-6. https://doi.org/10.1016/j.jretai.2016.12.008

Gulati, R., \& Garino, J. (1999). Get the right mix of bricks \& clicks. Harvard Rusiness Review, 78(3), 107-14.

Häubl, G., \& Trifts, V. (2000). Consumer decision making in online shopping environments: The effects of interactive decision aids. Marketing Science, 19(1), 4-21. https://doi.org/10.1287/mksc.19.1.4.15178

Hempsey M. (2012). Omnichannel loyalty designing the ultimate customer experience whitepaper. Kobie marketing 2012.

Henkel, J. (2002). Mobile payment. In Mobile commerce (pp. 327-351). Gabler Verlag.

Herhausen, D., Binder, J., Schoegel, M., \& Herrmann, A. (2015). Integrating bricks with clicks: retailer-level and channel-level outcomes of online-offline channel integration. Journal of Retailing, 91(2), 309-325. https://doi.org/10.1016/j.jretai.2014.12.009

Homburg, C., \& Giering, A. (2001). Personal characteristics as moderators of the relationship between customer satisfaction and loyalty-an empirical analysis. Psychology \& Marketing, 18(1), 43-66. https://doi.org/10.1002/1520-6793(200101)18:1<43::AID-MAR3>3.0.CO;2-I

Homburg, C., Jozić, D., \& Kuehnl, C. (2017). Customer experience management: toward implementing an evolving marketing concept. Journal of the Academy of Marketing Science, 45(3), 377-401. https://doi.org/10.1007/s11747-015-0460-7

Homburg, C., Vollmayr, J., \& Hahn, A. (2014). Firm value creation through major channel expansions: evidence from an event study in the United States, Germany, and China. Journal of Marketing, 78(3), 38-61. https://doi.org/10.1509/jm.12.0179

Ieva, M., \& Ziliani, C. (2017). Customer experience in retail banking: what touchpoints matter for customer loyalty?

iResearch. (2017). China's Third-Party Mobile Payment Report 2017.

iVend Retail. (2015). iVend Retail summit.

Johnson, M., \& Whang, S. (2002). E-business and supply chain management: an overview and framework. Production and Operations Management, https://doi.org/10.1111/j.1937-5956.2002.tb00469.x

Klosek, N. (2012). Creating the Omni-Channel. Dealerscope, 54(11), 1-4.

Ko, E., Kim, E. Y., \& Lee, E. K. (2009). Modeling consumer adoption of mobile shopping for fashion products in Korea. Psychology \& Marketing, 26(7), 669-687. https://doi.org/10.1002/mar.20294

Kollmann, T., Kuckertz, A., \& Kayser, I. (2012). Cannibalization or synergy? Consumers' channel selection in online-offline multichannel systems. Journal of Retailing and Consumer Services, 19(2), 186-194. 
https://doi.org/10.1016/j.jretconser.2011.11.008

Konuş, U., Verhoef, P. C., \& Neslin, S. A. (2008). Multichannel shopper segments and their covariates. Journal of Retailing, 84(4), 398-413. https://doi.org/10.1016/j.jretai.2008.09.002

Kopetz, H. (2011). Internet of things: Real time systems. Real Time Systems Series, 307-323. https://doi.org/10.1007/978-1-4419-8237-7_13

Kumar, S., Eidem, J., \& Noriega Perdomo, D. (2012). Clash of the e-commerce titans: A new paradigm for consumer purchase process improvement. International Journal of Productivity and Performance Management, 61(7), 805-830. https://doi.org/10.1108/17410401211263872

Kushwaha, T., \& Shankar, V. (2013, July). Are multichannel customers really more valuable? The moderating role of product category characteristics. American Marketing Association.

Kwon, W. S., \& Lennon, S. J. (2009). What induces online loyalty? Online versus offline brand images. Journal of Business Research, 62(5), 557-564. https://doi.org/10.1016/j.jbusres.2008.06.015

Lazaris, C., \& Vrechopoulos, A. (2014, June). From multi-channel to "omnichannel" retailing: review of the literature and calls for research. In the 2nd International Conference on Contemporary Marketing Issues (ICCMI).

Lewis, J., Foster, C., \& Whysall, P. (2013). Understanding the issues associated with going multi-channel: preliminary findings from an exploratory study in the UK retail sector, in the 17th EAERCD conference.

Lin, H. H. (2012). The effect of multi-channel service quality on mobile customer loyalty in an online-and-mobile retail context. The Service Industries Journal, 32(11), 1865-1882. http://dx.doi.org/10.1080/02642069.2011.559541

Lipstein, B. (1959, September). The dynamics of brand loyalty and brand switching. In Proceedings of the fifth annual conference of the advertising research foundation (pp. 101-108). New York: Advertising Research Foundation.

Mallat, N. (2007). Exploring consumer adoption of mobile payments - A qualitative study. Journal of Strategic Information Systems, 16, 413-432. https://doi.org/10.1016/j.jsis.2007.08.001

McConnell, J. D. (1968). The development of brand loyalty: an experimental study. Journal of Marketing Research, 13-19. https://doi.org/10.2307/3149788

McCormick, H., Cartwright, J., Perry, P., Barnes, L., Lynch, S., \& Ball, G. (2014). Fashion retailing-past, present and future. Textile Progress, 46(3), 227-321. http://dx.doi.org/10.1080/00405167.2014.973247

McKinsey (2014). The future of U.S. retail banking distribution. New York, NY.

Min, H., Ko, H. J., \& Ko, C. S. (2006). A genetic algorithm approach to developing the multi-echelon reverse logistics network for product returns. Omega, 34(1), 56-69. https://doi.org/10.1016/j.omega.2004.07.025

Montoya-Weiss, M. M., Voss, G. B., \& Grewal, D. (2003). Determinants of online channel use and overall satisfaction with a relational, multichannel service provider. Journal of the academy of marketing Science, 31(4), 448-458. https://doi.org/10.1177/0092070303254408

Moran J.W. \& Brightman B.K. "Leading organizational change." Career Development International, 6(2), $111-118$.

MuleSoft (n.d.). The secrets to enable omnichannel retailing. Retrieved from https://www.mulesoft.com/lp/whitepaper/api/retail-omnichannel

Mulpuru, S., Harteveldt, H. H., \& Roberge, D. (2011). Five retail ecommerce trends to watch in 2011. Reproduction, 1-8.

Murray, K. B., \& Häubl, G. (2008). Interactive consumer decision aids. In B. Wierenga, Handbook of Marketing Decision Models. New York, NY: Springer Science \& Business Media, LLC. https://doi.org/10.1007/978-0-387-78213-3_3

Napolitano, M. (2013). Omni-channel distribution: moving at the speed of" now". Logistics Management, 52(6).

Neslin, S. A., \& Shankar, V. (2009). Key issues in multichannel customer management: current knowledge and $\begin{array}{lllll}\text { future directions. Journal of Interactive Marketing, 23(1), } & \text { 70-81. }\end{array}$ https://doi.org/10.1016/j.intmar.2008.10.005

Neslin, S. A., Grewal, D., Leghorn, R., Shankar, V., Teerling, M. L., Thomas, J. S., \& Verhoef, P. C. (2006). 
Challenges and opportunities in multichannel customer management. Journal of Service Research, 9(2), 95-112. https://doi.org/10.1177/1094670506293559

Neslin, S. A., Jerath, K., Bodapati, A., Bradlow, E. T., Deighton, J., Gensler, S. \& Verhoef, P. C. (2014). The interrelationships between brand and channel choice. Marketing Letters, 25(3), 319-330. https://doi.org/10.1007/s11002-014-9305-2

Oh, L. B., Teo, H. H., \& Sambamurthy, V. (2012). The effects of retail channel integration through the use of information technologies on firm performance. Journal of Operations Management, 30(5), 368-381. https://doi.org/10.1016/j.jom.2012.03.001

OservatorioFedeltà Unipr. (2017). Loyalty Marketing Evolution: storie e protagonisti internazionali.

Pan, X., Ratchford, B. T., \& Shankar, V. (2004). Price dispersion on the Internet: A review and directions for future research. Journal of Interactive Marketing, 18(4), 116-135. https://doi.org/10.1002/dir.20019

Parker, R., \& Hand, L. (2009). Satisfying the Omnichannel Consumers Whenever and Wherever They Shop. IDC Retail Insights. IDC Retail Insights. Retrieved from http://www.amazon.com/SatisfyingOmnichannel-Consumers-Whenever-Wherever/dp/B002PW0G46

Patrício, L., Fisk, R. P., \& Falcão e Cunha, J. (2008). Designing multi-interface service experiences: the service experience blueprint. Journal of Service Research, 10(4), 318-334. https://doi.org/10.1177/1094670508314264

Pauwels, K., \& Neslin, S. A. (2015). Building with bricks and mortar: The revenue impact of opening physical stores in a multichannel environment. Journal of Retailing, 91(2), 182-197. https://doi.org/10.1016/j.jretai.2015.02.001

Pei, Y. L., Wang, S., \& Guo, T. (2017). Whether Adoption Drivers Differ between Click-and-mortar and Pure-play E-payment Services? WHICEB 2017 Proceedings. 60. Retrieved from http://aisel.aisnet.org/whiceb2017/60

Pentina, I., \& Hasty, R. W. (2009). Effects of multichannel coordination and e-commerce outsourcing on online retail performance. Journal of Marketing Channels, 16(4), 359-374. http://dx.doi.org/10.1080/10466690903188021

Piercy, N. (2012). Positive and negative cross-channel shopping behaviour. Marketing Intelligence \& Planning, 30(1), 83-104. https://doi.org/10.1108/02634501211193930

Piotrowicz, W., \& Cuthbertson, R. (2014). Introduction to the special issue information technology in retail: Toward omnichannel retailing. International Journal of Electronic Commerce, 18(4), 5-16.

Planet Retail. (2016 a). The connected retailer. Empowering the digital consumer.

Planet Retail. (2016 b). Global E-commerce trends 2016. Online grocery transforms the future.

Poncin, I., \& Mimoun, M. S. B. (2014). The impact of "e-atmospherics" on physical stores. Journal of Retailing and Consumer Services, 21(5), 851-859. https://doi.org/10.1016/j.jretconser.2014.02.013

Probert, D., \& Shehabuddeen, N. (1999). Technology road mapping: the issues of managing technology change. International Journal of Technology Management, 17(6), 646-661. https://doi.org/10.1504/IJTM.1999.002742

Rafaeli, A., Altman, D., Gremler, D. D., Huang, M. H., Grewal, D., Iyer, B., \& de Ruyter, K. (2017). The future of frontline research: Invited commentaries. Journal of Service Research, 20(1), 91-99. https://doi.org/10.1177/1094670516679275

Rapp, A., Baker, T. L., Bachrach, D. G., Ogilvie, J. \& Beitelspacher, L. S. (2015). Perceived customer showrooming behavior and the effect on retail salesperson self-efficacy and performance. Journal of Retailing, 91(2), 358-369. https://doi.org/10.1016/j.jretai.2014.12.007

Regalado, A. (2013). It's All E-Commerce Now. Technology Review, November, 4.

Rigby, D. (2011). The future of shopping. Harvard Business Review, 89(12), 65-76.

Rohm, A. J., \& Swaminathan, V. (2004). A typology of online shoppers based on shopping motivations. Journal of business research, 57(7), 748-757. https://doi.org/10.1016/S0148-2963(02)00351-X

Rosenblum, P., \& Kilcourse, B. (2013) Omni-channel 2013: The long road to adoption. Available at http://www.rsrresearch.com/2013/06/11/omni-channel-2013-the-long-road-to-adoption. 
Savisaari, A. (2016). Supply chain effects in creation of omnichannel customer experience in grocery retail. http://urn.fi/URN:NBN:fi:aalto-201603041456

Sawhney, M., \& Kotler, P. (2001). Marketing in the age of information democracy. Kellogg on Marketing, $386-408$

Schierz, P. G., Schilke, O., \& Wirtz, B. W. (2010). Understanding consumer acceptance of mobile payment services: An empirical analysis. Electronic Commerce Research and Applications, 9(3), 209-216. https://doi.org/10.1016/j.elerap.2009.07.005

Sciandra, M.R. (2014). Communication breakdown? Essays examining attention and distraction in technology mediated consumer communications. Working Paper, University of Pittsburgh. https://doi.org/10.2139/ssrn.2439202. http://d-scholarship.pitt.edu/id/eprint/23867

Selden, Larry, \& Ian C. MacMillan. (2006). Manage customer-centric innovation-systematically. Harvard business review, 84(4), 108.

Shah, D., Rust, R. T., Parasuraman, A., Staelin, R., \& Day, G. S. (2006). The path to customer centricity. Journal of Service Research, 9(2), 113-124. https://doi.org/10.1177/1094670506294666

Shankar, V., \& Balasubramanian, S. (2009). Mobile marketing: a synthesis and prognosis. Journal of Interactive Marketing, 23(2), 118-129. https://doi.org/10.1016/j.intmar.2009.02.002

Shankar, V., Smith, A. K., \& Rangaswamy, A. (2003). Customer satisfaction and loyalty in online and offline environments. International journal of Research in Marketing, 20(2), 153-175. https://doi.org/10.1016/S0167-8116(03)00016-8

Shankar, V., Venkatesh, A., Hofacker, C., \& Naik, P. (2010). Mobile marketing in the retailing environment: current insights and future research avenues. Journal of Interactive Marketing, 24(2), 111-120. https://doi.org/10.1016/j.intmar.2010.02.006

Sirkin, H., Keenan, P., \& Jackson, A. (2014). The hard side of change management. IEEE Engineering Management Review, 4(42), 132. https://doi.org/10.1109/EMR.2014.6966953

Srinivasan, S. S., Rolph, A., \& Kishore, P. (2002). Customer loyalty in e-commerce: An exploration of its antecedents and consequences. Journal of retailing 78(1), 41-50. https://doi.org/10.1016/S0022-4359(01)00065-3

Steinfield, C., \& Harry Bouwman, T. A. (2002). The dynamics of click-and-mortar electronic commerce: opportunities and management strategies. International Journal of Electronic Commerce, 7(1), 93-119. http://dx.doi.org/10.1080/10864415.2002.11044254

Strang, R. (2013). Retail without boundaries. Supply Chain Management Review, 17(6).

Ström, R., Vendel, M., \& Bredican, J. (2014). Mobile marketing: A literature review on its value for consumers and retailers. Journal of Retailing and Consumer Services, 21(6), 1001-1012. https://doi.org/10.1016/j.jretconser.2013.12.003

ThinkwithGoogle. (2016). Understanding How Micro-Moments Influence Consumers.

Van Nierop, J. E., Leeflang, P. S., Teerling, M. L., \& Huizingh, K. E. (2011). The impact of the introduction and use of an informational website on offline customer buying behavior. International Journal of Research in Marketing, 28(2), 155-165. https://doi.org/10.1016/j.ijresmar.2011.02.002

Verhagen, T., \& Van Dolen, W. (2009). Online purchase intentions: A multi-channel store image perspective. Information \& Management, 46(2), 77-82. https://doi.org/10.1016/j.ijresmar.2011.02.002

Verhoef, P. C. (2012). Multichannel customer management strategy. Handbook of Marketing Strategy, 135-50.

Verhoef, P. C., Kannan, P. K., \& Inman, J. J. (2015). From multi-channel retailing to omni-channel retailing: introduction to the special issue on multi-channel retailing. Journal of Retailing, 91(2), 174-181. https://doi.org/10.1016/j.jretai.2015.02.005

Verhoef, P. C., Neslin, S. A., \& Vroomen, B. (2007). Multichannel customer management: Understanding the research-shopper phenomenon. International Journal of Research in Marketing, 24(2), 129-148. https://doi.org/10.1016/j.ijresmar.2006.11.002

Wallace, D. W., Giese, J. L., \& Johnson, J. L. (2004). Customer retailer loyalty in the context of multiple channel strategies. Journal of Retailing, 80(4), 249-263. https://doi.org/10.1016/j.jretai.2004.10.002 
Ward, M. R. (2001). Will online shopping compete more with traditional retailing or catalog shopping? Netnomics, 3(2), 103-117. https://doi.org/10.1023/A:1011451228921

Webb, K. L. (2002). Managing channels of distribution in the age of electronic commerce. Industrial Marketing Management, 31(2), 95-102. https://doi.org/10.1016/S0019-8501(01)00181-X

Wind, Y., \& Mahajan, V. (2002). Convergence marketing. Journal of Interactive Marketing, 16(2), 64-79. https://doi.org/10.1002/dir.10009

Xia, F., Yang, L. T., Wang, L., \& Vinel, A. (2012). Internet of things. International Journal of Communication Systems, 25(9), 1101. https://doi.org/10.1002/dac.2417

Xu, J., Forman, C., Kim, J. B., \& Van Ittersum, K. (2014). News media channels: Complements or substitutes? Evidence from mobile phone usage. Journal of Marketing, 78(4), 97-112. https://doi.org/10.1509/jm.13.0198

Zhang, J., Farris, P. W., Irvin, J. W., Kushwaha, T., Steenburgh, T. J., \& Weitz, B. A. (2010). Crafting integrated multichannel retailing strategies. Journal of Interactive Marketing, 24(2), 168-180. https://doi.org/10.1016/j.intmar.2010.02.002

\section{Copyrights}

Copyright for this article is retained by the author(s), with first publication rights granted to the journal.

This is an open-access article distributed under the terms and conditions of the Creative Commons Attribution license (http://creativecommons.org/licenses/by/4.0/). 